\title{
Evolución piezométrica de las principales masas de agua subterránea de la cuenca alta del Guadiana. Periodo 1980-2018
}

\author{
Miguel Mejías Moreno y Jesús del PozoTejado \\ Instituto Geológico y Minero de España, Ríos Rosas 23, 28003 Madrid. \\ j.delpozo@igme.es; m.mejias@igme.es
}

\begin{abstract}
RESUMEN
El IGME lleva realizando el seguimiento piezométrico de la cuenca alta del Guadiana desde la década de los 70 del pasado siglo. Esta información hidrogeológica recopilada durante las últimas décadas, combinada con los registros climatológicos del mismo periodo, constituyen datos clave a la hora de entender la evolución piezométrica de la cuenca alta del Guadiana, en la que la mayoría de las MASb se encuentran en riesgo de no cumplir los objetivos medioambientales establecidos en la DMA. En el periodo 1980-2018 destaca el episodio húmedo 2009-2014, que tuvo lugar a continuación de un periodo de sequía intenso en el que se alcanzaron cotas piezométricas mínimas a nivel generalizado. La piezometría de las MASb analizadas ha seguido una tendencia coherente con la secuencia climatológica, si bien un estudio más detallado ha permitido identificar comportamientos diferenciados entre las MASb. Así, resulta que la cuenca alta del Guadiana ha registrado un proceso de descenso piezométrico desde el año 1980, considerado como escenario asimilable al estado natural, y recuperado parcialmente tras el citado episodio húmedo de 2009-2014. La recuperación parcial asociada a este periodo se ha producido de forma diferenciada para cada MASb, en función de sus características hidrogeológicas y de la posición que ocupa cada una en el bloque de la cuenca alta del Guadiana.
\end{abstract}

Palabras clave: cuenca alta del Guadiana, evolución piezométrica, hidrogeología, isopiezas, masa de agua subterránea en riesgo.

\section{Piezometric evolution of the principal groundwater bodies in the Upper Guadiana basin. Period 1980-2018}

\begin{abstract}
The IGME has been carrying out the piezometric monitoring in the upper Guadiana basin since the 1970s. This hydrogeological data collected during recent decades, combined with the climatological records of the same period, constitute key data for understanding the hydrogeological evolution of the upper Guadiana basin, in which the majority of the GWB are at risk of not meeting the environmental objectives established by the WFD. In the period 1980-2018, the wet period of 2009-2014 stands out, which followed a period of intense drought in which minimum piezometric measures were reached at a generalized level. The piezometry of the analyzed GWB has followed a trend consistent with the climatological sequence, although a more detailed study has allowed the identification of differentiated behaviours amongst the analyzed GWB. Thus, it turns out that the upper basin of the Guadiana has been registering a piezometric drawdown process since 1980, considered as a scenario like the natural state, partially recovered after the aforementioned wet period of 2009-2014. The partial recovery associated with this period has occurred in a differentiated way for each GWB, based on its hydrogeological characteristics and the position each occupies in the block of the upper Guadiana basin.
\end{abstract}

Keywords: groundwater body at risk; hydrogeology; piezometric evolution; piezometric contour line; upper Guadiana basin. 


\section{Introducción}

El Instituto Geológico y Minero de España (en adelante IGME) Ileva realizando el seguimiento hidrogeológico de la cuenca alta del Guadiana (CAG) desde el año 1973 hasta la actualidad, si bien, desde que en el año 2000 esta labor es transferida a los organismos de cuenca (Confederación Hidrográfica del Guadiana, en adelante $\mathrm{CHG}$ ), este lo hace en el marco de sus propias actividades.

Fruto del seguimiento del IGME, y de la puesta en común permanente de los datos recopilados por la CHG, se está en disposición de evaluar una información hidrogeológica muy valiosa respecto de la evolución piezométrica de la cuenca alta del Guadiana las últimas cuatro décadas.

El seguimiento hidrológico e hidrogeológico se completa con el análisis climatológico en el conjunto de la CAG, a partir de la recopilación y análisis de los datos de precipitación mensual de las 24 estaciones meteorológicas existentes en la zona, y obtenidos a partir del convenio firmado entre el IGME y la Agencia Española de Meteorología AEMET. El periodo temporal que abarcan los datos climatológicos es de 59 años en total, desde el año 1960 hasta el 2019.

En definitiva, se dispone de un conjunto de información que permite obtener una visión completa de la evolución piezométrica de las principales MASb de la cuenca alta del Guadiana en relación con la pluviometría de los últimos 45 años. El estudio se centra Ias MASb Mancha Occidental I, Mancha Occidental II, Rus-Valdelobos, Campo de Montiel y Sierra de Altomira, según orden de análisis.

\section{Objetivos}

El objetivo principal de este trabajo es la exposición de la síntesis del análisis hidrogeológico que viene realizando el IGME en las últimas décadas, a partir de los datos hidrogeológicos recopilados por el IGME y la CHG en la CAG. El análisis se extiende desde el año 1980 hasta el último año hidrológico con información disponible, 2017/18, a fecha de redacción de este artículo. La interpretación de resultados muestra una parte del análisis interanual de todos los datos disponibles, de los cuales aquí se expone una pequeña muestra.

Como objetivo secundario, se pretende hacer una revisión metodológica del seguimiento hidrogeológico llevado a cabo por el IGME, con el fin mejorar la obtención de datos, a partir de un análisis simplificado y metódico, que permita valorar el estado cuantitativo de las principales MASb de la CAG. En este sentido, los resultados del análisis propio aquí expuesto reflejan la necesidad de que los datos recopilados actualmente deberían ser completados con otros nuevos, que ayuden a obtener una interpretación más precisa del estado cuantitativo de la cuenca alta del Guadiana.

En última instancia, pero no por ello menos importante, los datos aquí reflejados permiten obtener una evaluación del estado de estas masas de agua estudiadas a fecha de 2018, masas que desde el año 2014 se encuentran declaradas en riesgo de no cumplir con los objetivos medioambientales recogidos en la Directiva Marco (2000/60/CE), en sus aspectos cuantitativo y químico (Tabla 1).

\begin{tabular}{|c|c|c|c|c|}
\hline MASb & NOMBRE & $\begin{array}{c}\text { FECHA DE } \\
\text { DECLARACIÓN DE } \\
\text { RIESGO }\end{array}$ & REFERENCIA & $\begin{array}{l}\text { TIPO DE RIESGO } \\
\text { DECLARADO }\end{array}$ \\
\hline 041.001 & Sierra de Altomira & $22 / 12 / 2014$ & $\begin{array}{c}\text { Anuncio } \\
\text { BOE-B-2014-45027 }\end{array}$ & $\begin{array}{l}\text { Cuantitativo } \\
\text { Químico }\end{array}$ \\
\hline 041.005 & Rus-Valdelobos & $22 / 12 / 2014$ & $\begin{array}{c}\text { Anuncio } \\
\text { BOE-B-2014-45024 }\end{array}$ & $\begin{array}{l}\text { Cuantitativo } \\
\text { Químico }\end{array}$ \\
\hline 041.006 & Mancha Occidental II & $22 / 12 / 2014$ & $\begin{array}{c}\text { Anuncio } \\
\text { BOE-B-2014-45026 }\end{array}$ & $\begin{array}{l}\text { Cuantitativo } \\
\text { Químico }\end{array}$ \\
\hline \multirow{2}{*}{041.007} & \multirow{2}{*}{ Mancha Occidental I } & \multirow{2}{*}{$22 / 12 / 2014$} & \multirow{2}{*}{$\begin{array}{c}\text { Anuncio } \\
\text { BOE-B-2014-45025 }\end{array}$} & Cuantitativo \\
\hline & & & & Químico \\
\hline \multirow{2}{*}{041.010} & \multirow{2}{*}{ Campo de Montiel } & \multirow{2}{*}{$22 / 12 / 2014$} & \multirow{2}{*}{$\begin{array}{c}\text { Anuncio } \\
\text { BOE-B-2014-45023 }\end{array}$} & Cuantitativo \\
\hline & & & & Químico \\
\hline
\end{tabular}

Tabla 1. Referencias de las declaraciones de riesgo de no cumplir con los objetivos medioambientales establecidas en la DMA en las MASb estudiadas.

Table 1. References of the risk statements of not meeting the environmental objectives established by the WFD in the studied GWB. 


\section{Localización}

La cuenca alta del Guadiana constituye el extremo más oriental de la cuenca hidrográfica del Guadiana. Comprende parte de las provincias de Ciudad Real, Cuenca, Toledo y Albacete, todas ellas pertenecientes a la comunidad autónoma de Castilla-La Mancha (Figura 1).

A grandes rasgos, la CAG incluye la divisoria hidrográfica con la cuenca del Júcar por el este, hasta la confluencia de los ríos Guadiana y Jabalón en el extremo occidental (al oeste de Ciudad Real). Limita al norte con la cuenca hidrográfica del Tajo, al este con la del Júcar, y al sur con la del Guadalquivir (Figura 1).

Dentro de la CAG, las MASb estudiadas en este artículo ocupan los extremos septentrional, en el caso de Sierra de Altomira, y meridional en el caso de Campo de Montiel, mientras que Mancha Occidental I, Mancha Occidental II y Rus-Valdelobos ocupan el sector central de la CAG, distribuidas de oeste a este, en el mismo orden (Figura 1).

\section{Metodología}

\section{Aspectos generales}

El orden de análisis de las MASb se ha adaptado al establecido por las unidades de gestión previas (sistemas acuíferos primero y unidades hidrogeológicas después) con idea de dar continuidad al seguimiento histórico previo a la estructuración en MASb como unidades de gestión.

El periodo temporal de análisis describe la evolución hidrogeológica de la CAG, desde un estadio asimilable al régimen natural en el año 1980, hasta el último año hidrológico completo 2017/18. En este artículo se considera al año 1980 como representativo de un escenario en el que, aun existiendo un moderado aprovechamiento de aguas subterráneas, las condiciones podían considerarse asimilables al régimen natural, en sentido hidrogeológico. A partir de este año, la incidencia de un cambio de tendencia pluviométrica hacia otra más seca, sumado al desarrollo socio-económico de la zona, producen un creciente e intensivo

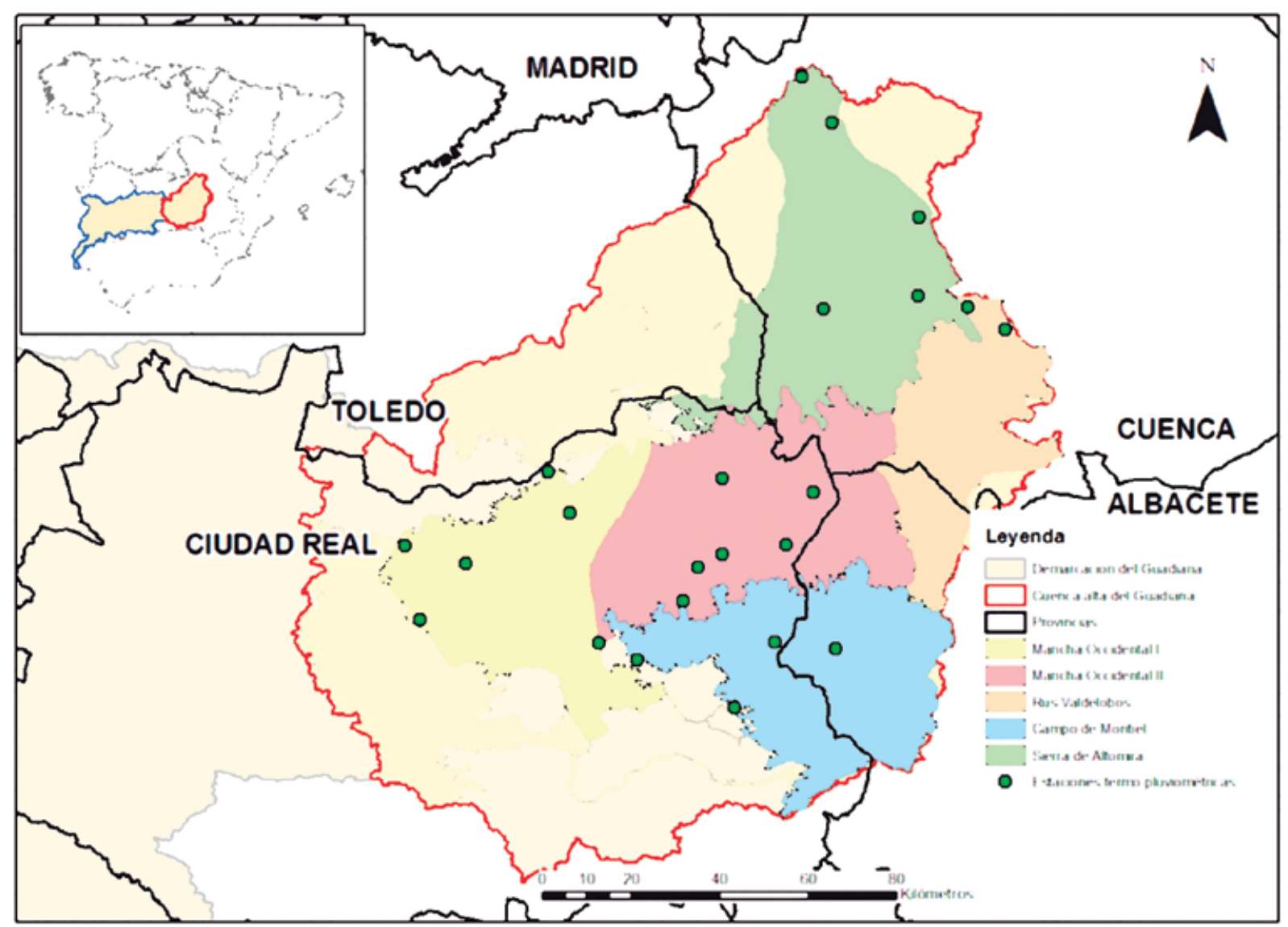

Figura 1. Localización de las MASb estudiadas en la cuenca alta del Guadiana y posición de las estaciones meteorológicas.

Figure 1. Position of the studied GWB in Upper Guadiana basin and location of the meteorological stations. 


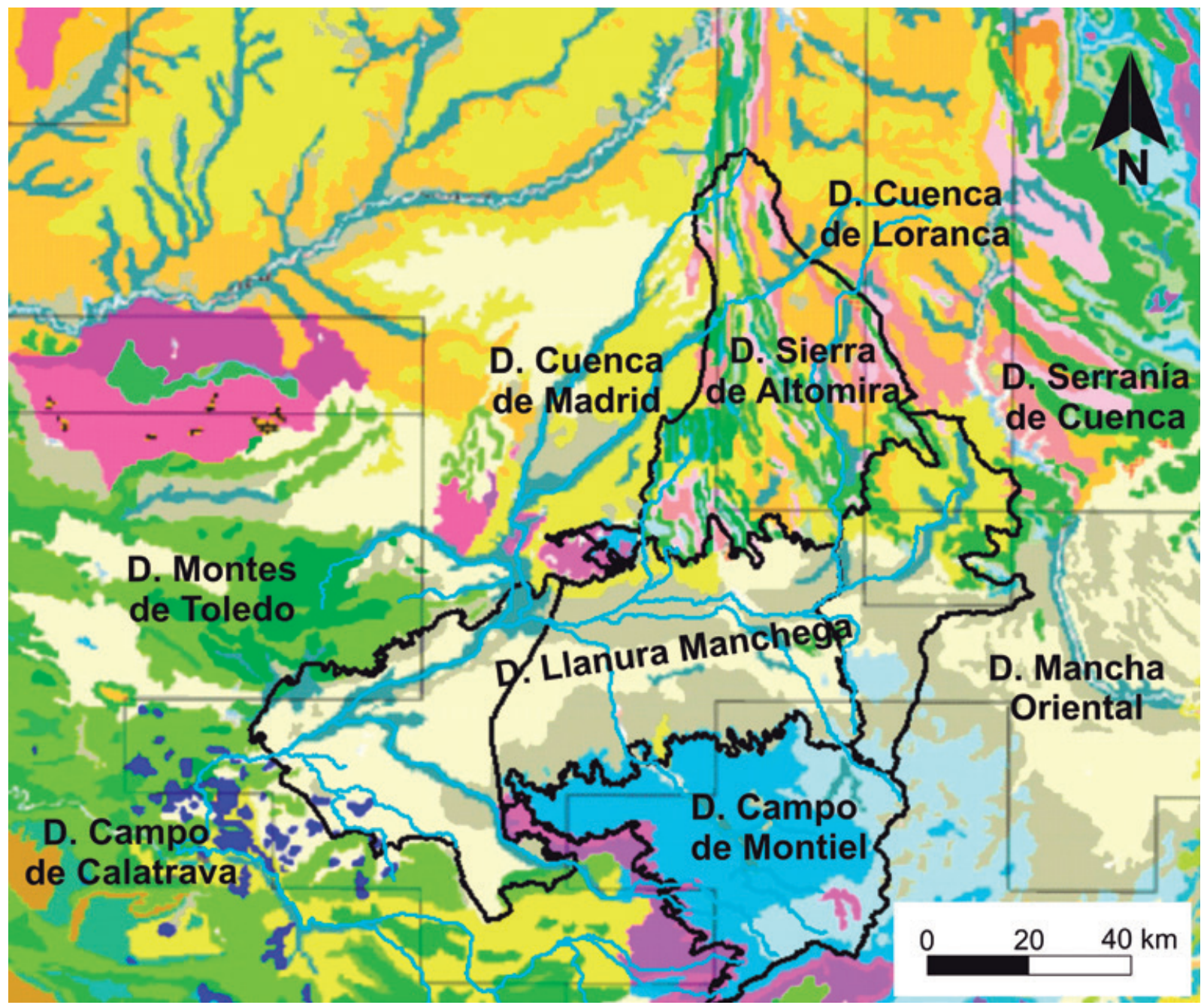

Figura 2. Dominios Geológicos más relevantes en la cuenca alta del Guadiana (modificado de Álvaro, M. et al., 1995).

Figure 2. Principal geological domains in the Upper Guadiana basin (modified from Álvaro, M. et al., 1995).

aprovechamiento de las aguas subterráneas, que tuvo como resultado la modificación del régimen natural de flujo, entendido este como la alteración significativa del patrón de circulación subterráneo y de los caudales de drenaje en las zonas de descarga.

\section{Análisis climatológico}

Para el análisis climatológico se han recopilado y analizado los datos de pluviometría mensual en un total de 24 estaciones termo-pluviométricas, de las cuales 6 estaciones se encuentran en la MASb Mancha Occidental I, 7 en Mancha Occidental II, 2 en Rus-Valdelobos, 5 estaciones en de Campo de Montiel y 4 en Sierra de Altomira (Figura 1 y Tabla 2).

Los datos disponibles en estas estaciones se correlacionan y estudian en conjunto, puesto que son representativas de la variabilidad climatológica del conjunto de la CAG, si bien se tratan individualmente, puesto que cada una de ellas es representativa del entorno local en el que se sitúa (condiciones de altitud, latitud, orografía, etc.). La caracterización de la climatología para cada una de las MASb se establece en base a las estaciones situadas en su ámbito y a la representatividad de sus datos, seleccionándose una estación como representativa de cada MASb en función de su posición, amplitud de la serie de registro y representatividad de su evolución de los datos de precipitación.

El análisis de la serie de datos de precipitación mensual se realiza mediante un gráfico que incluye los valores de precipitación anual y el valor promedio de la serie. Se incluye también la curva de desviaciones acumuladas de la precipitación anual con respecto a 
la media, a partir de la cual se establecen las secuencias climáticas de tendencia seca y húmeda.

\section{Piezometría}

La amplitud del área abarcada en la zona de estudio incluye, necesariamente, zonas de diferente comportamiento a nivel hidrogeológico dentro de una misma MASb, efecto más evidente cuando se abarca un área que engloba a varia de ellas (sector central de la CAG, identificada con la antigua U.H. Mancha Occidental). La pretensión de dar continuidad al seguimiento piezométrico histórico previo a la definición de las MASb actuales, ha llevado, anteriormente, a comparar piezómetros de difícil correlación espacial en la cuenca alta del Guadiana. En este artículo, se agrupan los piezó- metros por MASb independientes, si bien se mantiene un estudio conjunto para el sector central de la CAG (MASb Mancha Occidental I, Mancha Occidental II y Rus-Valdelobos).

Para minimizar el efecto local en la comparación de piezometría, se ha hecho una selección de piezómetros representativos en cada una de las MASb, cuyo comportamiento se puede simplificar mediante un tratamiento unitario. Los puntos así designados se han seleccionado en base a la representatividad de su evolución piezométrica sea representativa de la tendencia evolutiva del conjunto de la MASb, sin verse afectada por efectos piezométricos locales. En la selección también se ha tenido en cuenta la amplitud de la serie de registro, dando preferencia a aquellos puntos con la serie más extensa. En la MASb Sierra de Altomira no se aplica esta simplificación, y se han

\begin{tabular}{|c|c|c|c|c|c|}
\hline \multirow{2}{*}{$\begin{array}{c}\text { CODIGO } \\
\text { IDENTIFICATIVO }\end{array}$} & \multirow[b]{2}{*}{ NOMBRE } & \multirow[b]{2}{*}{ PROVINCIA } & \multirow[b]{2}{*}{$\begin{array}{l}\text { ALTITUD } \\
\text { m s.n.m. }\end{array}$} & \multicolumn{2}{|c|}{ LOCALIZACIÓN } \\
\hline & & & & $\begin{array}{c}\text { X UTM } \\
\text { ETRS } 89 \text { H30 }\end{array}$ & $\begin{array}{c}\text { Y UTM } \\
\text { ETRS } 89 \text { H30 }\end{array}$ \\
\hline 4017 & ARGAMASILLA ALBA (PACHECAS) & CIUDAD REAL & 690 & 488882,3 & 4323400,3 \\
\hline 4075 & VILLARES DEL SAZ & CUENCA & 865 & 542171,2 & 4410167,7 \\
\hline 4104 & ARENALES DE SAN GREGORIO & CIUDAD REAL & 644 & 497662,7 & 4351230,2 \\
\hline 4093 & OSA DE LA VEGA & CUENCA & 763 & 520589,0 & 4389618,0 \\
\hline 4007B & OSSA DE MONTIEL 2 & ALBACETE & 905 & 523282,7 & 4312638,3 \\
\hline 4012 & RUIDERA & CIUDAD REAL & 790 & 509586,7 & 4314150,4 \\
\hline 4016 & ARGAMASILLA DE ALBA & CIUDAD REAL & 671 & 492158,4 & 4331072,2 \\
\hline 4026 & CARRIZOSA & CIUDAD REAL & 854 & 500443,2 & 4299379,5 \\
\hline $4032 \mathrm{~A}$ & LA SOLANA, INSTITUTO & CIUDAD REAL & 768 & 478535,0 & 4310197,5 \\
\hline 4034 & MEMBRILLA & CIUDAD REAL & 664 & 469883,1 & 4313924,5 \\
\hline 4045 & CARRASCOSA DEL CAMPO & CUENCA & 895 & 522476,1 & 4431605,0 \\
\hline 4051 & VELLISCA & CUENCA & 950 & 515794,2 & 4442040,2 \\
\hline 4079 & VILLALGORDO DEL MAROUESADO & CUENCA & 856 & 541888,1 & 4392376,7 \\
\hline 4083 & CASTILLO DE GARCIMUÑOZ & CUENCA & 925 & 553173,2 & 4389979,6 \\
\hline 4084 & HONRUBIA & CUENCA & 820 & 561698,3 & 4384863,6 \\
\hline 4097 & SOCUELLAMOS & CIUDAD REAL & 674 & 518289,6 & 4348106,1 \\
\hline 40991 & SOCUELLAMOS (LAS REJAS) & CIUDAD REAL & 700 & 512078,7 & 4336226,2 \\
\hline 4103 & TOMELLOSO & CIUDAD REAL & 662 & 497657,5 & 4333997,2 \\
\hline 4108 & PUERTO LAPICE & CIUDAD REAL & 675 & 458297,1 & 4352666,2 \\
\hline 4109 & VILLARTA DE SAN JUAN & CIUDAD REAL & 625 & 463162,2 & 4343362,2 \\
\hline $4112 U$ & LASTABLAS DE DAIMIEL & CIUDAD REAL & 619 & 439700,3 & 4331977,7 \\
\hline 4120 & CARRION DE CALATRAVA & CIUDAD REAL & 615 & 429357,3 & 4319146,8 \\
\hline 4124 & MALAGON & CIUDAD REAL & 610 & 426051,3 & 4335855,8 \\
\hline 4106 & ALAMEDA DE CERVERA & CIUDAD REAL & 650 & 488937,6 & 4346243,12 \\
\hline
\end{tabular}

Tabla 2. Listado de estaciones meteorológicas en la zona de estudio.

Table 2. Meteorological station list in the study area. 
analizado el conjunto de piezómetros que integran la red en 2018, dadas las evidencias de compartimentación interna existentes (Martínez M. y Díaz J.A., 2013; Mejías M. y del Pozo J., 2018).

Para el análisis de la evolución piezométrica entre diferentes años hidrológicos (más húmedos o más secos), se ha tomado el criterio de comparar periodos de niveles de aguas altas, una vez que, en condiciones normales, ya ha tenido lugar el grueso de las precipitaciones invernales que afectan a la recarga de los acuíferos, y no han dado comienzo los riegos sistemáticos propios de los meses de primavera y verano. Como mes de referencia se adoptan los valores piezométricos del mes de marzo (mes que incorpora las precipitaciones de los meses de otoño e invierno previos, pero también el cese de las extracciones). Se han comparado las piezometrías correspondientes al periodo de aguas altas (marzo del año correspondiente), año a año entre sí, y todas ellas con las del último año disponible 2018, para evaluar el estado cuantitativo más reciente. De todos los datos comparados, se muestran en este artículo únicamente aquellos que destacan por representar ítems significativos en la evolución piezométrica de la zona, seleccionados expresamente para caracterizar la evolución hidrogeológica de la CAG.

Se han considerado como fechas significativas la situación piezométrica del año 1980 en el que, como se ha mencionado anteriormente, ya se producía un aprovechamiento notable, pero aún se mantenía el esquema natural de flujo subterráneo con drenaje a través de las principales surgencias occidentales de descarga (Ojos del Guadiana, Ojos del Gigüela y los cauces de ambos ríos). También se consideran como años significativos el 2009 (último mínimo piezométrico en la CAG consecuencia de un periodo climatológico de sequía prolongada), el año 2014 (último máximo piezométrico ligado al periodo húmedo 2009-2013), y por último el 2017 (referencia de los niveles piezométricos del año hidrológico anterior a 2018).

Los valores piezométricos realmente comparados corresponden a profundidades de nivel piezométrico en metros (PNP) que, a efectos de cuantificar variaciones, son igualmente comparables que las cotas piezométricas absolutas.

Las variaciones piezométricas entre dos periodos concretos, se han analizado en función del valor promedio de las variaciones en los piezómetros representativos de una MASb, y unificados todos en un único bloque en el caso del sector central de la CAG para estimar las variaciones del volumen de agua almacenado. En las MASb Campo de Montiel y Sierra de Altomira, se han diferenciado sectores de comportamiento relativamente independiente, si bien los resultados se han unificado para el conjunto de la MASb en la comparación final siguiendo la misma metodología para todas las MASb.

Se ha procurado mantener una misma línea de seguimiento hidrogeológico para todas las MASb, si bien el grado de aplicabilidad no es igual en todas. La no aplicabilidad, o poca representatividad del método de análisis en determinadas MASb, se considera un resultado por sí mismo, a ser tenido en cuenta en el diseño de los futuros planes de seguimiento de la CAG.

\section{Hidrometría}

Tras un periodo de interrupción de 30 años aproximadamente, el drenaje de agua subterránea a través de Los Ojos del Guadiana (MASb Mancha Occidental I) volvió a producirse en el año 2012. A partir de este año, el seguimiento del drenaje subterráneo en esta zona comenzó a controlarse periódicamente mediante el control foronómico en los ríos Guadiana y Azuer. La cuantificación de la aportación subterránea en este punto se hace mediante aforos diferenciales entre secciones del río situadas aguas arriba y aguas abajo de Los Ojos del Guadiana (zona de polisurgencia).

La evolución del caudal subterráneo drenado en esta zona se analiza de forma temporal, estableciendo una relación del caudal drenado a través de Los Ojos del Guadiana con la piezometría de esta zona.

\section{Marco geológico}

En la CAG se identifican dominios geológicos con características geológicas y estructurales muy diferentes. De los dominios presentes, cabe mencionar aquellos en los que se circunscriben las MASb tratadas en este artículo, entre ellos a destacar el dominio de la Llanura Manchega, el de Campo de Montiel y el de Sierra de Altomira. Quedan fuera de la zona estudiada los dominios de Campo de Calatrava, Montes de Toledo, Serranía de Cuenca, Mancha Oriental y los de las cuencas de Madrid y de Loranca (Figura 2).

No es objeto de este artículo hacer una descripción detallada de las características geológicas de cada uno de los dominios implicados. Esta se encuentra disponible en la bibliografía que trata la geología de la CAG (Vera J.A., 2004). De manera muy resumida, a continuación se incluyen unas breves pinceladas de los aspectos geológicos más relevantes de cada uno de los dominios.

La Llanura Manchega se define a partir del relleno sedimentario de una fosa tectónica con zócalo paleozoico, sobre el que se disponen, de forma discordante, materiales cenozoicos y mesozoicos (Portero J.M. et al.1988). La cuenca se rellena a partir de sedimentos 
cuaternarios puntuales, dispuestos sobre una potente serie de sedimentos terciarios de origen continental (Mioceno superior-Plioceno). En profundidad, se localiza la serie mesozoica compuesta por potentes niveles carbonatados de origen marino, presente únicamente en el subsuelo de las MASb Mancha Occidental II y Rus-Valdelobos y, bajo la misma, la serie triásica compuesta básicamente por arcillas, margas yesíferas y calizas de origen continental.

El dominio de Campo de Montiel se define a partir de una potente cobertera tabular subhorizontal carbonatada de edad jurásica, apenas afectada por el plegamiento alpino. En profundidad, y de forma discordante, se encuentran los materiales triásicos evaporíticos y el basamento hercínico (Montero E. y Rincón P.J., 2004).

El dominio de Sierra de Altomira se caracteriza por presentar una serie de afloramientos mesozoicos de morfología lineal, de dirección aproximada N-S a NO$\mathrm{SE}$, constituidos por el eje de uno o varios anticlinales apilados, con vergencia al oeste (Querol R., 1989). Estos afloramientos responden a la charnela de los anticlinorios apilados a partir de las escamas cabalgantes mesozoicas, cuyo nivel de despegue se produce en las facies evaporíticas triásicas del Keuper. Los materiales terciarios y cuaternarios se localizan como relleno de las cuencas sedimentarias interpuestas. En profundidad, de forma discordante a la serie mesozoica, se dispone el basamento hercínico.

\section{Marco hidrogeológico}

\section{Hidrogeología}

La hidrogeología de la zona de estudio tiene características diferentes, consecuencia de los distintos ámbitos geológicos representados en las MASb analizadas en este artículo.

En el sector central de la CAG se definen dos niveles acuíferos, fundamentalmente. El acuífero superior, constituido por los niveles carbonatados y detríticos continentales de edad pliocena, que se extienden a lo largo de toda su superficie. Presentan una potencia superior a los $200 \mathrm{~m}$ en su sector central y disminuye, de forma brusca, hacia sus márgenes norte y sur. En el caso de su extremo occidental la reducción es progresiva, favoreciéndose el drenaje subterráneo a favor de los principales cauces y la formación de importantes humedales (Ojos del Guadiana, Tablas de Daimiel) por reducción de la potencia del acuífero. El acuífero profundo está constituido por niveles carbonatados de edad mesozoica, y se extiende bajo las MASb Rus-Valdelobos y Mancha Occidental II. No se encuentra presente en el subsuelo de Mancha Occidental I por el acuñamiento progresivo de la serie mesozoica hacia el oeste. Aflora puntualmente en varios sectores de la MASb Rus-Valdelobos, presentando un régimen de acuífero confinado o semiconfinado en el resto de la CAG.

Sierra de Altomira y Campo de Montiel se sitúan respectivamente en los márgenes norte y sur, topográfica y estructuralmente más elevados con respecto al bloque hundido o surco tectónico de la Llanura Manchega. Así, el acuífero mesozoico (profundo en el sector central de la CAG) llega a aflorar en superficie en ambos dominios, y constituye el acuífero principal en las respectivas MASb. En la de Campo de Montiel afloran en superficie los niveles carbonatados jurásicos del Lías, escasamente afectados por plegamiento y con una elevada permeabilidad por karstificación. En Sierra de Altomira se encuentran presentes los acuíferos carbonatados de edad jurásica y cretácica, intensamente plegados y apilados durante la orogenia alpina. Estos presentan una elevada permeabilidad por karstificación, y actúan como acuífero libre en las charnelas de los anticlinorios mesozoicos aflorantes, y como semiconfinado a confinado a medida que la serie mesozoica se hunde bajo las cuencas de rellenos terciarios interpuestas entre afloramientos lineales mesozoicos.

\section{Modelo hidrogeológico conceptual}

El conjunto de la CAG puede ser considerado como una unidad, si se tienen en cuenta las transferencias laterales de agua subterránea que se producen entre ellas (Martínez-Cortina L. et al., 2011). El rasgo principal que define el modelo hidrogeológico conceptual de la CAG es el drenaje, superficial y subterráneo, desde sus flancos septentrional (Sierra de Altomira) y meridional (Campo de Montiel) hacia el sector central (Figura 3), identificado geológicamente con la Llanura o Surco Manchego.

El modelo conceptual describe este sector central de la CAG como eje centralizador de las aguas subterráneas, en el que la circulación subterránea sigue un patrón de dirección este-oeste y sentido oeste, hacia el tramo medio de la cuenca del Guadiana (en condiciones naturales). En el interior de la MASb Rus-Valdelobos se identifica una divisoria de aguas subterráneas, de posición variable en función de la situación hidrodinámica (López Gutiérrez J. et al., 2013). Esta divisoria independiza el flujo en sentido oeste, hacia la cuenca alta del Guadiana, del que toma dirección este, hacia la Demarcación Hidrográfica del Júcar. Esta divisoria subterránea Guadiana-Júcar tiene su equivalente en la MASb de Campo de Montiel, situándose esta en su sector tercio oriental (Martínez-Cortina L., 2008). Otra divisoria subterránea, de posición más imprecisa, que- 


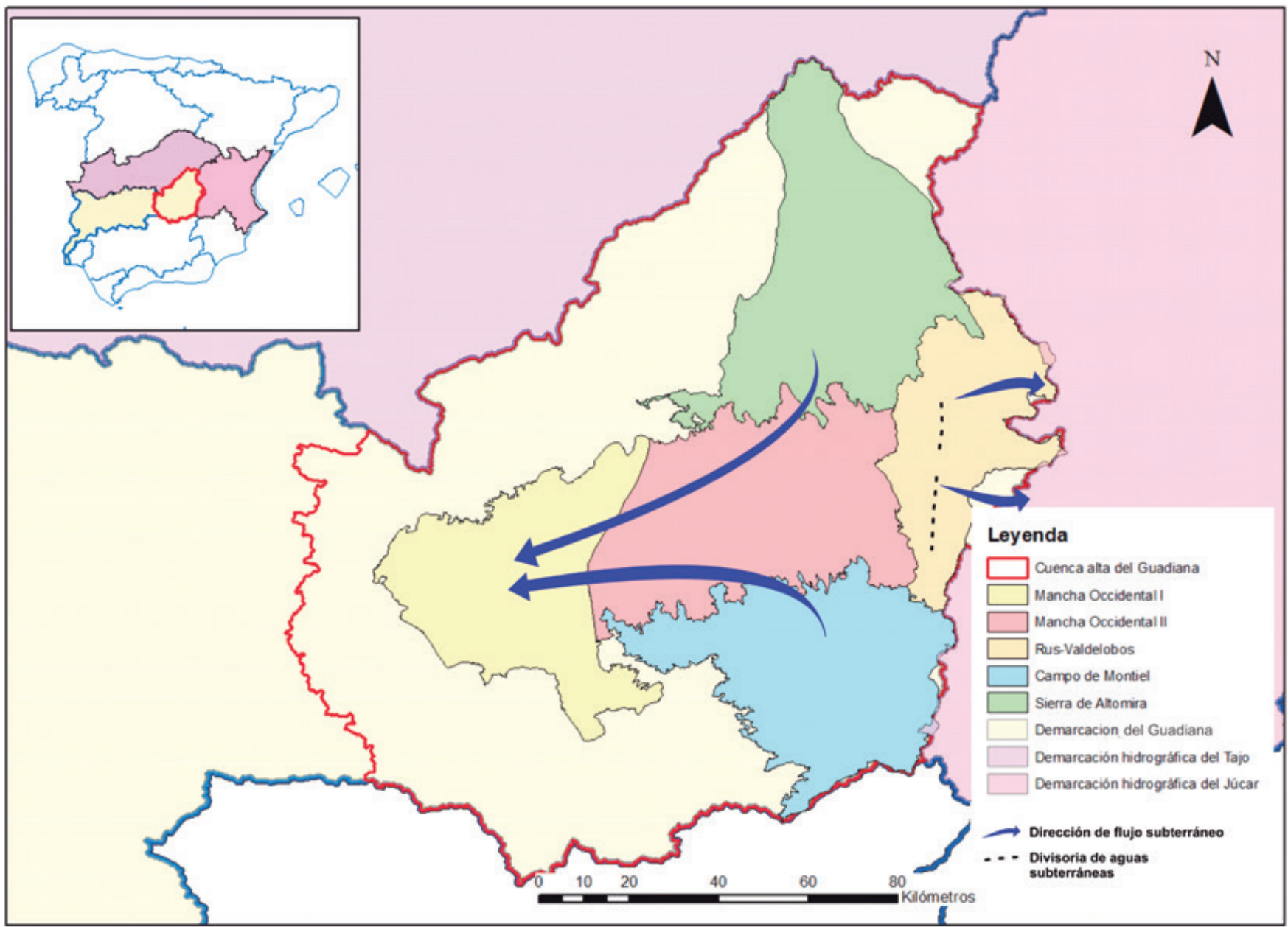

Figura 3. Patrón de flujo subterráneo en el sector central de la cuenca alta del Guadiana.

Figure 3. Groundwater flux pattern in the central part of the Upper Guadiana basin.

daría definida en el sector occidental de esta MASb, y determinaría los flujos subterráneos dirigidos hacia el extremo occidental. En esta zona la descarga se sitúa próxima al contacto con los aluviales del Jabalón y el Azuer, si bien esta se produciría básicamente a través del drenaje de manantiales.

En el modelo hidrogeológico (Figura 3) se representa exclusivamente las relaciones hidrogeológicas subterráneas que afectan al sector central de la CAG, objeto de este trabajo. Se obvian en esta figura las relaciones hidrogeológicas con otras demarcaciones (Tajo, Júcar y Guadalquivir) y con los aluviales del Azuer y Jabalón en las MASb Campo de Montiel.

\section{Análisis climatológico}

En este apartado, como ejemplo, se incluye el análisis de la serie de precipitación anual de la estación $4112 \mathrm{U}$ Las Tablas de Daimiel, seleccionada como represen- tativa de las condiciones climatológicas de la MASb Mancha Occidental I. Previamente se han analizado los datos de todas la estaciones disponibles y se han seleccionado, aquellas con mayor representatividad (a nivel de MASb), con datos actualizados, y con una serie de registro lo más completa posible.

\section{Estación 4112U Las Tablas de Daimiel}

En la figura 4 se presenta el gráfico de análisis correspondiente a la estación $4112 \mathrm{U}$ Las Tablas de Daimiel. La precipitación media anual, para la serie comprendida entre los años hidrológicos 1960/61 a 2017/18 es de $416,8 \mathrm{~mm}$. Los valores de precipitación anual, a lo largo de este periodo de 58 años, varían entre un valor mínimo de $208,8 \mathrm{~mm}$ (año hidrológico 1994/95) y un máximo de 706,6 mm (año 1961/62). El último año hidrológico con datos completos 2017/18, presenta un valor anual de precipitación de 498,06 mm, valor su- 


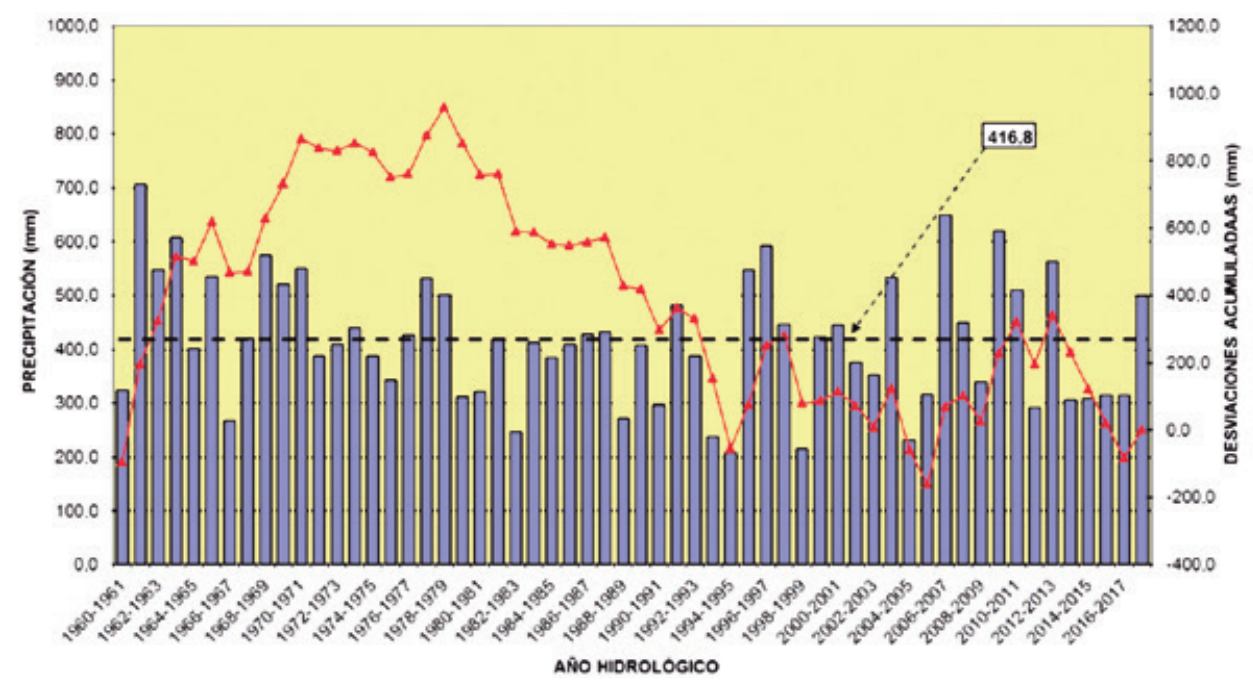

Figura 4. Precipitación anual en la estación de Las Tablas de Daimiel (4112U).

Figure 4. Annual rainfall sequence in the Tablas de Daimiel climatologic station (4112U).

perior al de los anteriores cuatro años hidrológicos en los que la precipitación no superó los $315 \mathrm{~mm}$.

En la estación $4112 \mathrm{U}$ de Las Tablas de Daimiel, el año hidrológico 2017/18 catalogado como húmedo, rompe con la serie de 4 años secos anteriores, con una precipitación anual un 20 \% superior a la media anual. La curva de desviaciones acumuladas refleja este hecho (Figura 4), pasando de un tramo de pendiente negativa (2012/13 a 2016/17) a un tramo con incipiente pendiente positiva (año hidrológico 2017/18) que refleja la ruptura puntual del tramo seco anterior. La continuidad temporal de esta secuencia húmeda dependerá de los valores de precipitación de los años posteriores al año hidrológico 2017/18, si bien, con los datos existentes en el momento de redacción de este artículo, el año 2018/19 muy probablemente se clasificará como seco.

\section{Análisis de la secuencia de precipitación en el con- junto de la CAG}

Se ha hecho un análisis similar al anterior para todas las estaciones de la CAG. De todas ellas, como ya se ha dicho, se han seleccionado una estación como representativa de las MASb respectiva, para la comparación de los datos de precipitación de esta con la evolución piezométrica de la MASb correspondiente. En la tabla 3 se incluye un resumen de los datos más importantes de las estaciones seleccionadas.

Tras hacer un análisis unitario de las secuencias de precipitación registradas en las estaciones pluviométricas en el conjunto de estaciones meteorológicas, cabe destacar las importantes variaciones entre las precipitaciones entre años secos y húmedos, que presenta diferencias superiores a $500 \mathrm{~mm}$ (Figura $4 \mathrm{y}$

\begin{tabular}{|c|c|c|c|c|c|c|c|c|c|c|}
\hline \multirow{2}{*}{ Código } & \multirow{2}{*}{ Nombre } & \multirow{2}{*}{ MASb } & \multirow{2}{*}{$\begin{array}{c}\text { Periodo } \\
\text { de } \\
\text { registro }\end{array}$} & \multirow{2}{*}{$\begin{array}{c}P \text { anual } \\
\text { media } \\
\text { mm }\end{array}$} & \multirow{2}{*}{$\begin{array}{c}\text { P anual } \\
2017 / 18 \\
\mathrm{~mm}\end{array}$} & \multirow{2}{*}{$\begin{array}{l}\text { Calificación } \\
\text { año } \\
\text { hidrológico } \\
2017 / 18\end{array}$} & \multicolumn{2}{|c|}{$\begin{array}{l}\text { P máxima } \\
\text { anual }\end{array}$} & \multicolumn{2}{|c|}{ P mínima anual } \\
\hline & & & & & & & $\mathbf{m m}$ & Año & $\mathbf{m m}$ & Año \\
\hline 4016 & $\begin{array}{c}\text { ARGAl } \\
\text { DE }\end{array}$ & $\begin{array}{r}\text { Man } \\
\text { Occide }\end{array}$ & $\begin{array}{r}1960 / 5 \\
2017\end{array}$ & 04,3 & 630,5 & $\mathrm{H}$ & 835,0 & 9/10 & 135,0 & 1994/95 \\
\hline 4083 & $\begin{array}{l}\text { CASTILLO DE } \\
\text { GARCIMUÑOZ }\end{array}$ & $\begin{array}{c}\text { Rus- } \\
\text { Valdelobos }\end{array}$ & $\begin{array}{c}1960 / 91 \mathrm{a} \\
2017 / 18\end{array}$ & 507,8 & 587,4 & Húmedo & 813,7 & $1968 / 69$ & 277,4 & 1998/99 \\
\hline 4012 & RUIDERA & $\begin{array}{c}\text { Campo de } \\
\text { Montiel }\end{array}$ & $\begin{array}{c}1960 / 91 \mathrm{a} \\
2017 / 18 \\
\end{array}$ & 444,9 & 477,1 & Medio & 786,2 & $1968 / 69$ & 198,8 & $1994 / 95$ \\
\hline 4075 & $\begin{array}{c}\text { VILLARES DEL } \\
\text { SAZ }\end{array}$ & $\begin{array}{l}\text { Sierra de } \\
\text { Altomira }\end{array}$ & $\begin{array}{c}1978 / 79 a \\
2017 / 18\end{array}$ & 517,3 & 670 & Húmedo & 786,0 & $1968 / 69$ & 216,8 & $2004 / 05$ \\
\hline
\end{tabular}

Tabla 3. Principales datos de precipitación en las estaciones seleccionadas como representativas para las MASb correspondientes. Table 3. Main rainfall data in the stations selected as representative for the corresponding GWB 
Tabla 3). Se concluye además que las series húmedas (tramos ascendentes de la curva de desviaciones acumuladas) tienen una duración más corta (Figura 4) que las secuencias climáticas secas (tramos descendentes de la curva de desviaciones acumuladas), las cuales se extienden a lo largo de periodos de tiempo más prolongados (3-4 años de media para las series húmedas, por 8-10 años para las secas). Durante las secuencias secas, puede darse algún año húmedo intercalado puntualmente que, por sí solo, sin una continuidad añadida, no altera la continuidad del periodo seco como parece suceder en el año hidrológico 2017/18.

\section{Descripción de la secuencia de precipitación en la CAG en el periodo de registro}

A partir del año hidrológico 1960/61, la serie histórica comienza con una importante secuencia húmeda hasta el año 1977/78. A continuación sigue un extenso periodo seco hasta el año 1994/95. Le sigue un nuevo y breve ciclo húmedo, entre los años 1995/96 al 1997/98, seguido, de nuevo, de un extenso periodo seco, desde este último año hasta el 2008/09. Dentro de esta secuencia seca se produce la incidencia de algún año húmedo intercalado. En el otoño de 2009 se inicia un importante ciclo húmedo, que se prolonga durante cuatro años hidrológicos hasta el 2012/13. A partir del año hidrológico 2013/14, y hasta el año 2016/17, tiene lugar un periodo seco variable en cuanto a su intensidad en las estaciones analizadas. El último año hidrológico considerado 2017/18, caracterizado por una tasa de precipitación anual superior a la media, interrumpe el ciclo seco anterior 2013-2017 en toda la CAG, si bien no se puede afirmar que suponga un cambio de ciclo hasta no conocer los valores de precipitación de los años posteriores.

\section{Evolución hidrogeológica de las MASb del sector cen- tral de la Cuenca Alta del Guadiana}

La evolución hidrogeológica histórica de las tres masas centrales de la cuenca alta del Guadiana (Mancha Occidental I, Mancha Occidental II y Rus-Valdelobos) se analiza, en este artículo, de forma independiente en cuanto a la variación de niveles piezométricos para cada una, pero de forma conjunta para el trazado del mapa de isopiezas del sector central de la CAG, dada la conexión hidrogeológica entre ellas. La conexión subterránea entre las MASb habilita la posibilidad de trazar un mapa de isopiezas unitario para todo el sector central de la CAG, tal y como se viene haciendo desde los primeros trabajos relacionados con la hidrogeología de la cuenca alta del Guadiana (IGME, 1979; Fabregat V. et al., 1989).

\section{Evolución piezométrica del periodo 1980-2018}

En el sector central de la cuenca alta del Guadiana se han definido un total de 18 puntos representativos, dis-

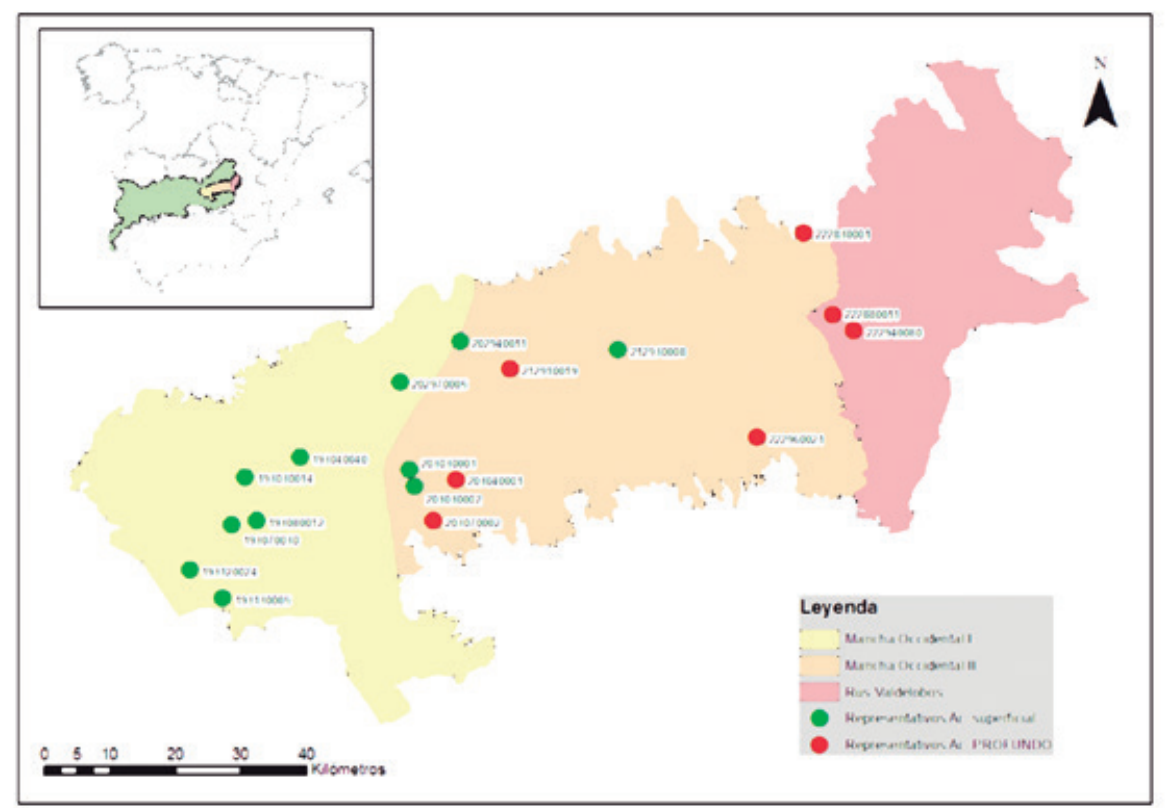

Figura 5. Piezómetros representativos en el sector central de la cuenca alta del Guadiana (MASb Mancha Occidental I, Mancha Occidental Il y Rus-Valdelobos).

Figure 5. Representative piezometers in the central part of the Upper Guadiana basin (GWB Mancha Occidental I, Mancha Occidental II and Rus-Valdelobos). 
tribuidos por toda la superficie (Figura 5). En un primer análisis, se han representado las gráficas de evolución piezométrica temporal de los piezómetros representativos de las tres MASb (Figura 6). Sin entrar a valorar los aspectos diferenciables que escapan al objetivo de este trabajo, la tónica común en todos ellos para el periodo 1980-2018 refleja una evolución piezométrica de tendencias piezométricas ascendentes y descendentes que reproducen fielmente la secuencia de ciclos húmedos y secos definidos en el epígrafe anterior. Así, los ciclos climáticos húmedos generan ascensos piezométricos en función de la intensidad y duración del evento pluviométrico, mientras que los ciclos secos (de mayor duración) llevan asociados importantes descensos, más acusados por el incremento de las extracciones inherentes a los episodios de sequía prolongada.

Tras un análisis, grosso modo, de los promedios de variación piezométrica de los años seleccionados en los piezómetros representativos, se obtienen datos significativos que definen la evolución piezométrica general del sector central de la CAG.

A partir del año 1980 hasta 1989 (Figura 6), comienza con un proceso de descenso generalizado de niveles, con un valor próximo a los 1,8 m/año; le sigue un periodo en el que se acentúa los descensos hasta 2,3 m/año, atribuible a un episodio de sequía y al consecuente incremento de la extracciones (1989-1995); a continuación, se produce un ascenso de los niveles de 2,5 m/año, asociado al periodo húmedo 1995-1998; a partir del año 2000 , se inicia un nuevo proceso de descenso piezométrico promediado en 1,3 m/año (20002003), interrumpido por el año hidrológico húmedo $2003 / 04$, en el que se invierte la tendencia con ascenso de 1,3 m/año (2003-2005); en el año 2005 comienza un proceso descendente de 2,4 m/año que se atenúa hasta la práctica estabilización a partir de 2007 (periodo 20052009); a continuación, el importante episodio húmedo que dio comienzo en 2009, y se extendió hasta la primavera del 2014, produjo el ascenso de niveles más importante desde que se tiene registro, con un incremento promediado en las tres MASb centrales de $18,3 \mathrm{~m}$ (2009-2014); a partir del año 2014 tiene lugar un nuevo periodo seco hasta 2017 que se refleja en descensos de 2,2 m en Mancha Occidental I, 4,5 en Mancha Occidental II y 4,6 m en Rus-Valdelobos (2014-2017).

En el año hidrológico 2017/18, último con datos completos, se produjeron importantes precipitaciones que contrastan con el periodo de cuatro años secos anterior. Este evento de precipitación aún no ha tenido un reflejo significativo en la piezometría de la CAG (Figura 7), más allá del ascenso esperable posterior al periodo de aguas bajas. En comparación con los niveles del último máximo piezométrico (año 2014), en marzo de 2018 se contabiliza un descenso promedio

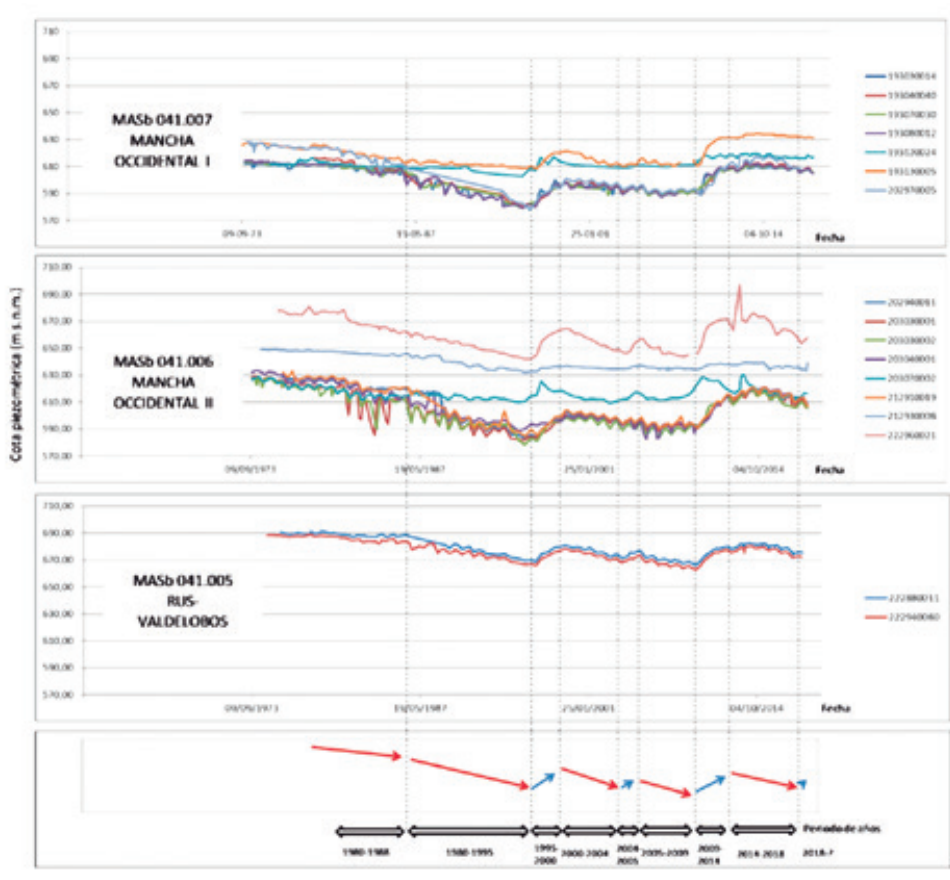

Figura 6. Evolución piezométrica de los piezómetros representativos del sector central de la cuenca alta del Guadiana y síntesis de la tendencia piezométrica general 1980-2018.

Figure 6. Piezometric evolution in the representative piezometers of the central part of the Upper Guadiana basin, and synthesis of the general piezometric trend 1980-2018.

de 2,64 m en Mancha Occidental I, 8,5 m en Mancha Occidental II, y 7,61 m en Rus-Valdelobos, reflejo del ciclo seco de 4 años hidrológicos anteriores al 2018.

\section{Análisis del estado hidrogeológico en 2018}

El análisis de la variación de niveles de la tabla 4 se presenta, para cada MASb de forma individual, en forma de promedio de la variación de niveles en los respectivos piezómetros representativos. Asimismo, se incluye un valor de variación promedio para el conjunto de las tres MASb del sector central de la CAG. A continuación se incluye un breve análisis de los datos para cada una de las MASb.

\section{MASb 041.007 Mancha Occidental I}

La comparativa de los niveles piezométricos registrados en marzo de 2018 y marzo de 1980 pone de manifiesto un descenso promedio de 1,2 $\mathrm{m}$ en el año actual con respecto a la situación de 1980. Este descenso es relativamente pequeño en comparación con los descensos identificados en las MASb vecinas $(12,1 \mathrm{~m}$ y 14,8 m en Mancha Occidental Il y Rus-Valdelobos, respectivamente). La diferencia se atribuye, por un lado, 


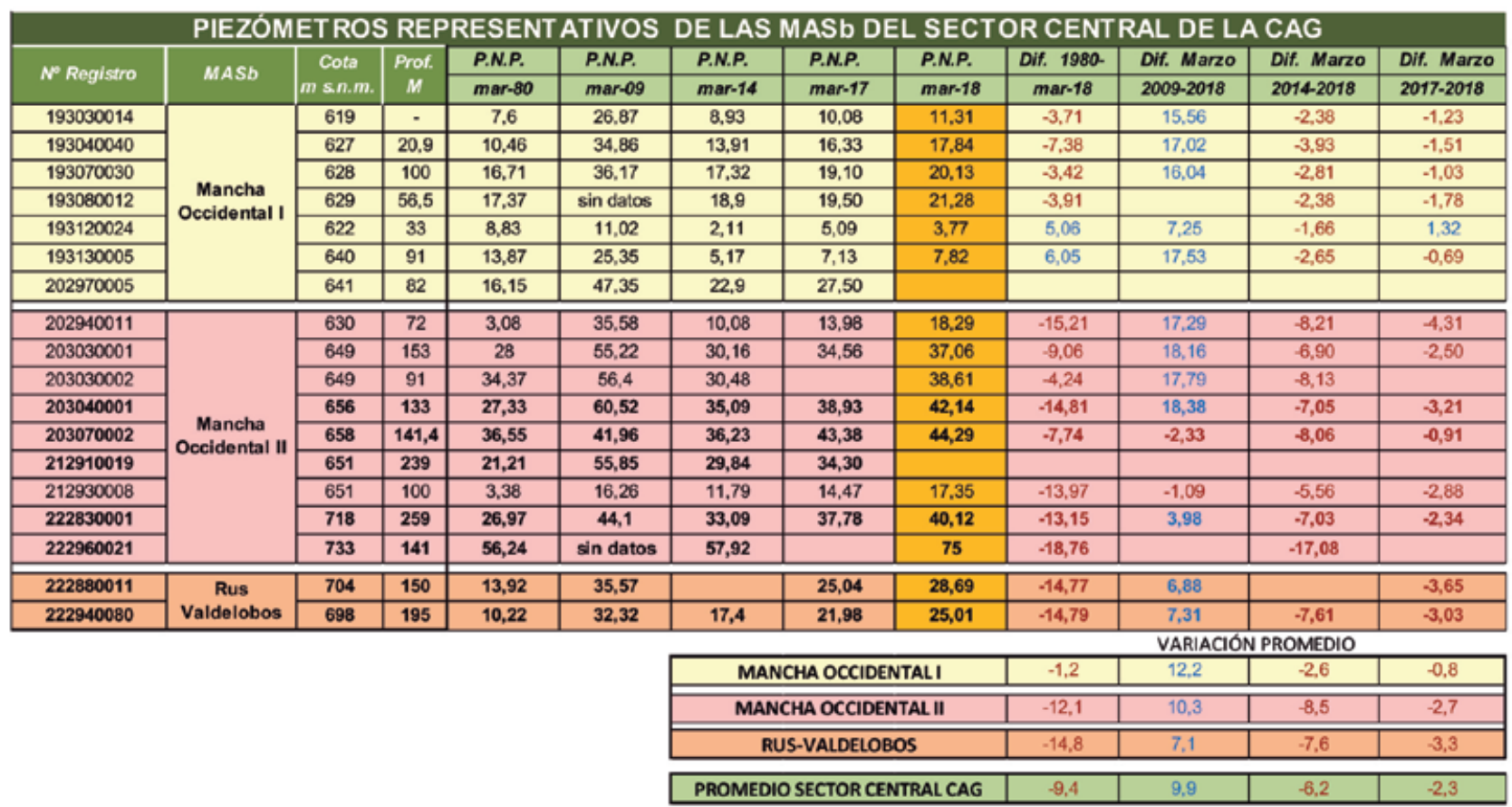

Tabla 4. Medidas de profundidad de nivel piezométrico en los piezómetros representativos de las MASb Mancha Occidental I, Mancha Occidental Il y Rus-Valdelobos y diferencias entre estas (en metros).

Table 4. Piezometric level depth in the representative piezometers of the GWB Mancha Occidental I, Mancha Occidental II and Rus-Valdelobos.

a la mayor proximidad de la formación acuífera a la superficie y, por tanto, una mayor rapidez en mostrar los efectos de las precipitaciones de la primavera de 2018; por otro lado, por ser esta MASb receptora de un aporte subterráneo con componente inercial consecuencia del periodo húmedo 2009-2014, procedente desde las MASb situadas aguas arriba, tal y como se apunta en del Pozo y Mejías (2017).

En la comparación de medidas entre los años 2009 y 2018, el mayor ascenso se ha producido en la MASb Mancha Occidental I (12,2 m, frente a los 10,3 m de Mancha Occidental II y 7,1 m de Rus-Valdelobos). En el periodo seco 2014-2018, el descenso ha sido menor en comparación con las otras dos MASb $(2,6 \mathrm{~m}$, frente a los 8,5 m de Mancha Occidental Il y 7,6 m de Rus-Valdelobos). Se observa, por tanto, una menor incidencia relativa de los episodios húmedos y secos. También se pone en evidencia la idea de que la MASb Mancha Occidental I aún presenta un aporte (o influencia) del agua subterránea infiltrada durante el periodo húmedo 2009-2014 en forma de transferencia lateral desde las MASb situadas aguas arriba en el sentido del flujo subterráneo.

La comparación entre la situación de aguas altas de los años 2017 y 2018 muestra un descenso de nivel piezométrico de $0,82 \mathrm{~m}$ de media, descenso más moderado que en el resto de las MASb $(2,7$ en mancha Occidental II y 3,3 m el Rus-Valdelobos). Por otro lado, las notables precipitaciones del invierno y primavera de 2018 aún no han tenido reflejo ascendente en la piezometría, si bien es probable que hayan conseguido atenuar el efecto descendente (hecho que no ocurre en las MASb Mancha Occidental II y Rus-Valdelobos) puesto que, en el caso de Mancha Occidental I, el acuífero se sitúa próximo a la superficie.

Se puede concluir, por tanto, que la MASb Mancha Occidental I presenta un efecto de amortiguación piezométrica mayor que el de las MASb situadas aguas arriba en el sector central de la CAG. La transferencia lateral subterránea desde las masas situadas aguas arriba en el sentido del flujo subterráneo, sumado a los aportes rápidos por infiltración directa de lluvia, dotan a esta masa de un comportamiento inercial que favorece su capacidad de regulación hidrogeológica.

\section{MASb 041.006 Mancha Occidental II}

La diferencia de niveles entre el año 1980 y 2018 refleja un descenso promedio de nivel piezométrico de 12,1 $\mathrm{m}$, diez veces superior al de la masa anterior. Existe un 
notable descenso de niveles entre la situación de 1980 (asimilable al estado natural) y la de 2018.

Entre los años 2009 (anterior mínimo histórico) y 2018, se identifica un ascenso promedio de 10,3 m, que muestra el importante efecto de recuperación asociado al periodo húmedo 2009-2014 que se mantiene todavía en 2018.

La diferencia de piezometría entre los periodos de aguas altas de los años 2017 y 2018 muestra un descenso medio de nivel de 2,7 m, valor significativamente mayor que el de la MASb Mancha Occidental I $(0,8$ $\mathrm{m})$, pero aún menor que en Rus-Valdelobos $(3,3 \mathrm{~m})$. El descenso piezométrico en marzo de 2018 es importante, debido a la secuencia de 4 años hidrológicos anteriores secos y a que, a fecha de marzo de 2018, la piezometría de esta MASb aún no refleja la incidencia de las importantes precipitaciones del año hidrológico 2017/18 debido a su comportamiento inercial.

Esta masa es la que recibe un mayor volumen de agua mediante transferencia subterránea procedente de las MASb Sierra de Altomira, al norte, y, sobre todo, Campo de Montiel, al sur (Figura 3). La inciden- cia de los periodos secos tiene, por tanto, un efecto negativo amplificado en la piezometría de los años siguientes en esta MASb, sumado a que la incidencia de los episodios húmedos (máximos piezométricos) tiene reflejo en la piezometría más tarde que en las MASb de las que recibe aporte subterráneo.

La magnitud de las variaciones, por su parte, es mayor que en la MASb situada aguas abajo (Mancha Occidental I) debido a que, estructuralmente, sus horizontes acuíferos se encuentran a mayor profundidady presentan una potencia mayor.

\section{MASb 041.005 Rus-Valdelobos (sector occidental)}

Se trata de una masa con cierta complejidad hidrogeológica en sentido este-oeste, si bien su mitad occidental (a la que corresponde este análisis) tiene un comportamiento asimilable al de la MASb Mancha Occidental II. Los dos piezómetros representativos se ubican próximos al límite oeste de la masa, minimizando así las incertidumbres debidas a la presencia de la divisoria hidrogeológica de posición variable Gua-

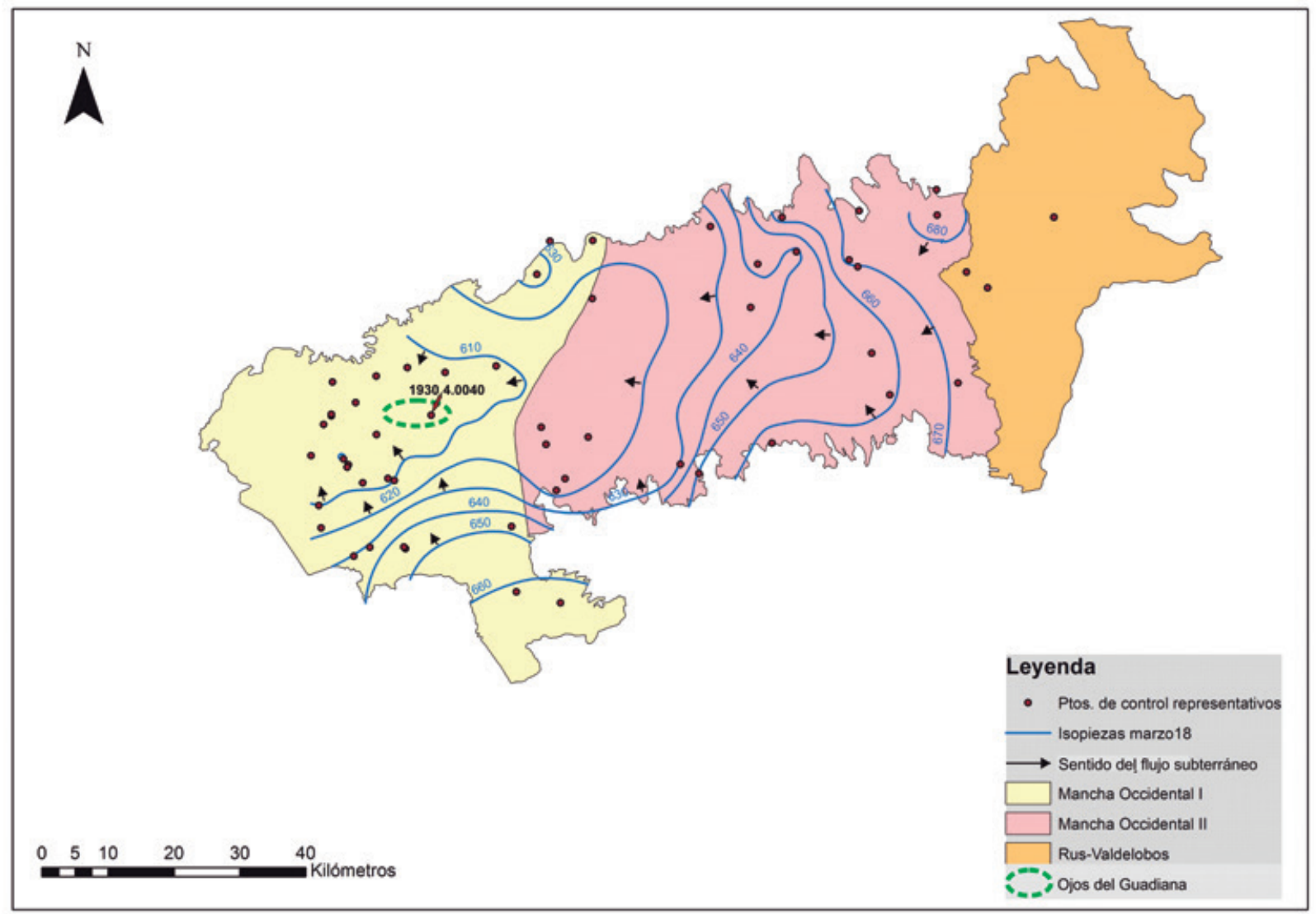

Figura 7. Mapa de isopiezas (en m s.n.m.) del sector central de la CAG correspondiente al periodo de aguas altas de 2018. Figure 7. Piezometric contour lines ( $m$ a.s.l.) in the central part of the Upper Guadiana basin, March 2018. 
diana-Júcar situada, aproximadamente, en el sector central de la MASb (López Gutiérrez J. et al., 2013).

La diferencia piezométrica promedio entre los años 1980 y 2018 refleja un descenso de 14,8 m, muy superior al de Mancha Occidental I, y ligeramente superior al de Mancha Occidental II. Entre el mínimo de 2009 y la situación del año 2018 se observa un episodio de recuperación con ascenso promedio de 7,1 m, bastante inferior al ascenso promedio registrado en las dos masas anteriores. Entre los periodos de aguas altas de los años 2017 y 2018 se produce un descenso de 3,3 $\mathrm{m}$ de media.

\section{Mapa de isopiezas y dirección del flujo subterráneo}

El mapa de isopiezas (y direcciones del flujo resultantes) de las tres masas centrales se elabora a partir de los datos de la red de seguimiento piezométrico controlada por el IGME. En sentido hidrogeológico, las tres masas de agua funcionan como una única unidad (Mancha Occidental I, Mancha Occidental II y el sector occidental de Rus-Valdelobos), en la que el flujo de agua subterránea se ve influido por cualquier actuación que tenga lugar en cada una de ellas, de forma individual. Por tanto, se presenta el mapa de isopiezas del conjunto de las tres masas del sector central de la CAG, correspondientes al periodo de aguas altas de marzo de 2018 (Figura 7). Además, se han empleado los datos de todos los piezómetros representativos, tanto los que controlan el acuífero superficial terciario como los que controlan el acuífero profundo mesozoico. La diferencia de nivel piezométrico entre ambos es prácticamente nula $y$, pese a que el acuífero profundo presenta un cierto retardo en la respuesta a las precipitaciones (o a la ausencia de estas), se pone de manifiesto la conexión efectiva natural entre ambos niveles. Este efecto se ve favorecido por los miles de pozos que comunican ambos acuíferos, considerándose válida la representación conjunta de la piezometría de ambos acuíferos (Mejías M., 2007).

Las isopiezas de 2018 presentan una dirección de flujo subterráneo este-oeste, en sentido oeste, con un gradiente medio, para todo el bloque, de $4 \cdot 10^{-4}$ (Figura 7). Las isopiezas definen una dirección de flujo indicativa de la influencia, a nivel subterráneo, de los aportes laterales desde las MASb Sierra de Altomira al norte de Mancha Occidental II, y desde Campo de Montiel, al sur. El flujo se dirige hacia el sector occidental, en el que, históricamente, se sitúa el área de drenaje natural del sistema (Ojos del Guadiana y cauce del río Guadiana). El flujo subterráneo se restauró a su dirección original en el año 2012, consecuencia del efecto del episodio húmedo 2009-2014. Anteriormente a este año 2012, el flujo presentaba una depresión piezométrica en la zona, provocada por las intensas extracciones del sector central de la MASb Mancha Occidental I (del Pozo J. y Mejías M., 2017).

Desde el año hidrológico 2011/12, el flujo subterráneo mantiene una dirección similar a la de principios de los años ochenta del pasado siglo: esto es una dirección de flujo subterráneo en sentido de este a oeste, desde la divisoria de aguas subterráneas con la cuenca del Júcar, situada en la MASb Rus-Valdelobos, a lo largo de todo el sector central de la CAG hacia el oeste. No se han restaurado de igual manera los caudales drenados en régimen no alterado, resultando mucho menores (en torno a un $15 \%$ en la situación más favorable) en comparación a los registrados a comienzos de los años 80 (del Pozo J. y Mejías M., 2017).

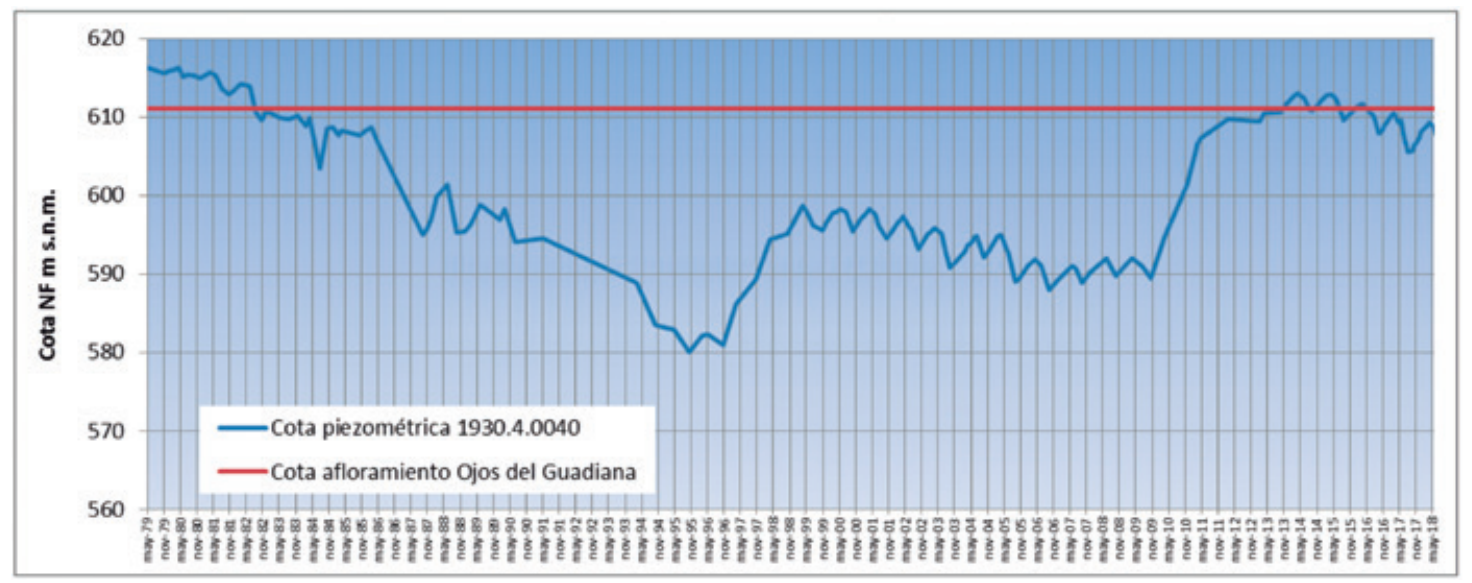

Figura 8. Evolución piezométrica del punto de control 193040040 frente a los datos de precipitación anual de la estación pluviométrica de LasTablas de Daimiel

Figure 8. Piezometric evolution in the piezometer 193040040 vs. annual rainfall in the Tablas de Daimiel station. 


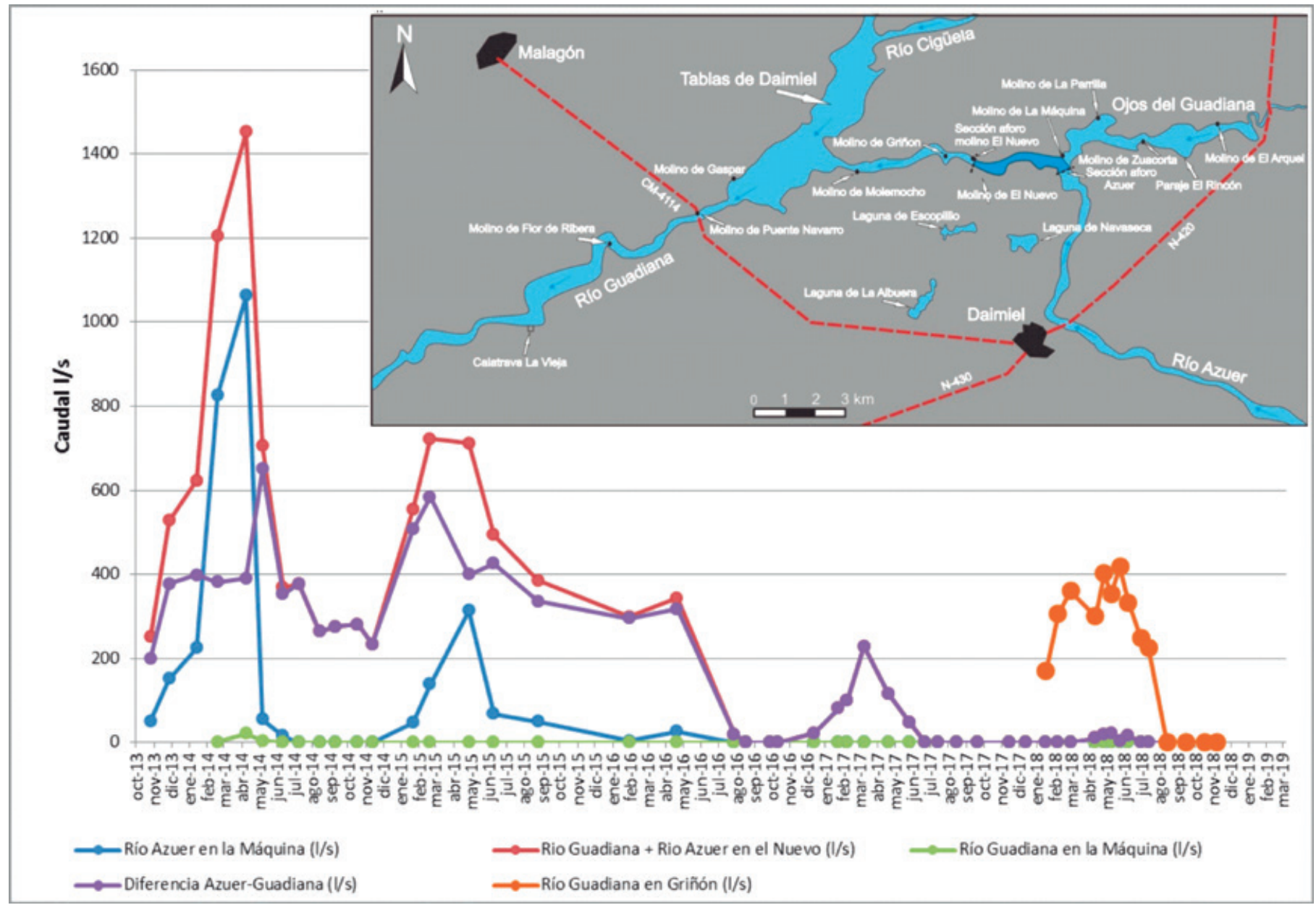

Figura 9. Caudales de aforo medidos en los ríos Guadiana y Azuer en el periodo 2013-2018.

Figure 9. Gauging inflows in the Guadiana and Azuer rivers, 2013-2018 period.

\section{Piezometría en el entorno de Los Ojos del Guadiana}

Considerando lo expuesto en los apartados anteriores, el flujo subterráneo del sector central de la CAG circula hacia el oeste (MASb Mancha Occidental I), hacia la zona de drenaje de este sector, principalmente a través del cauce del río Guadiana, en el tramo comprendido entre Los Ojos del Guadiana y el parque nacional de las Tablas de Daimiel. Por tanto, la piezometría del sector central de la CAG se puede evaluar a partir del seguimiento de la evolución del drenaje subterráneo del sistema a través de Los Ojos del Guadiana, convirtiéndose este punto en un indicador excelente del "estado de salud" hidrogeológico de las tres masas de agua centrales de la CAG (ver posición en la figura 7).

El caudal de drenaje en esta zona tiene una relación directa con la cota piezométrica del acuífero en esta área. Se ha tomado como dato representativo de la piezometría en este sector la cota alcanzada en el piezómetro 1930.4.0040. Este punto de observación se sitúa en Los Ojos del Guadiana, y el IGME lo mide sistemáticamente desde el año 1979.

La zona de surgencia de agua de Los Ojos del Guadiana actuó como tal hasta 1984, si bien en los últimos años tuvo un pronunciado comportamiento estacional (Figura 8). Una altura piezométrica por encima de la cota de 611 m s.n.m. produce la descarga continua de agua subterránea. En marzo de 2018, la cota de agua subterránea en este piezómetro era de $609,0 \mathrm{~m}, 1,5$ metros inferior a la del periodo de aguas altas del año anterior (610,5 m s.n.m. en marzo de 2017). Las precipitaciones del invierno de 2018 hacen ascender la cota piezométrica en este punto, pero lejos de alcanzar los 611 m s.n.m. de altura piezométrica necesarios para que se produzca el drenaje en superficie. Con respecto al máximo relativo de $613,0 \mathrm{~m}$, que se alcanzó en el mes de abril de 2014, el descenso es de prácticamente 


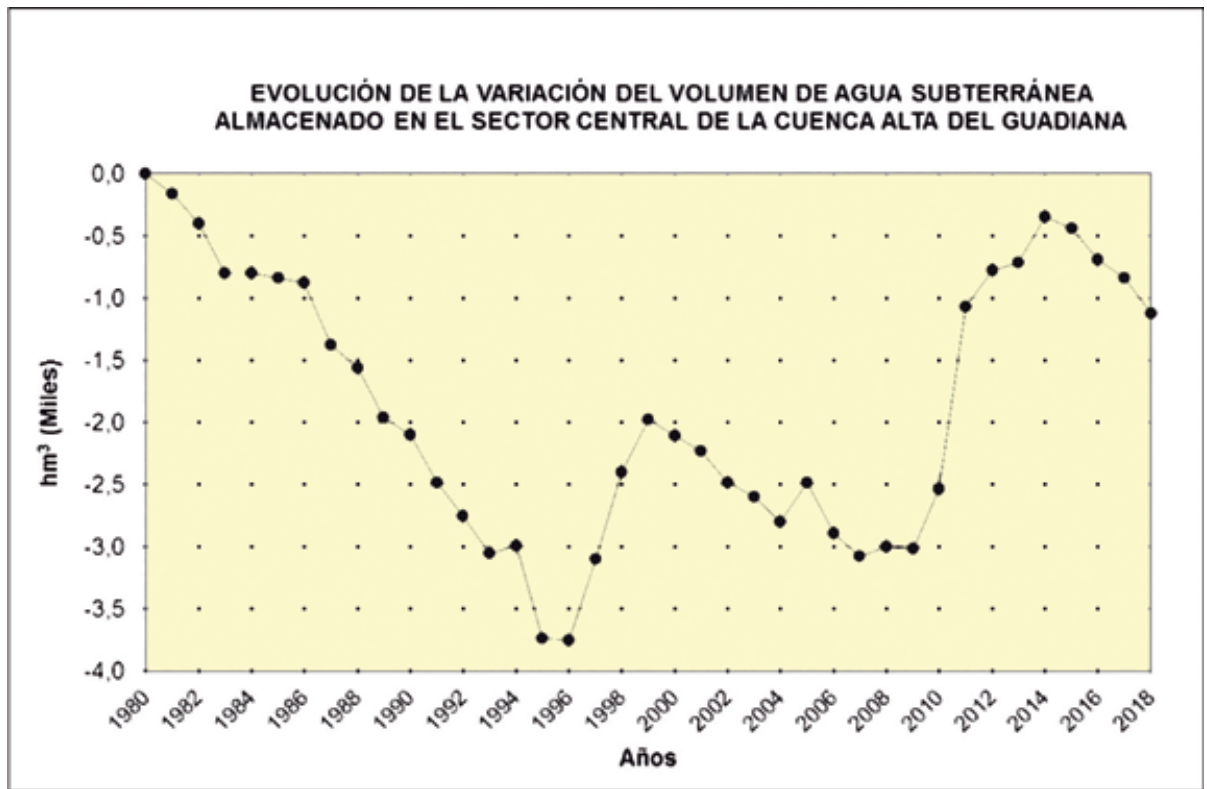

Figura 10. Evolución de la variación del volumen de agua subterránea almacenado en el ámbito de las tres MASb centrales de la CAG. Figure 10. Evolution of the volume of the stored groundwater in the central part of the Upper Guadiana basin.

de 4 metros desde el periodo seco que dio comienzo en el año 2014. En estos años, la cota piezométrica en este punto ha seguido una tendencia general descendente, si bien la surgencia de agua en superficie se ha recuperado puntualmente tras los periodos húmedos anuales hasta mayo de 2017. Desde esta fecha hasta septiembre de 2018, la cota piezométrica se ha mantenido por debajo de la $611 \mathrm{~m}$ s.n.m. de referencia, resultando el drenaje nulo en este punto a partir de entonces.

Entre mayo de 2017 y marzo de 2018 el drenaje del río se ha producido aguas abajo, a la altura del molino de Griñón (cota 609,5 m s.n.m.). Esta cota es la que, aproximadamente, refleja la altura piezométrica del piezómetro de control 1930.4.0040 en marzo de 2018.

\section{Drenaje de aguas subterráneas}

Otro indicador representativo del estado cualitativo del sector central de la CAG es la cuantificación del volumen de agua circulante en el río Guadiana a la altura del tramo de Los Ojos del Guadiana (MASb Mancha Occidental I). Desde octubre de 2013, mensualmente el IGME lleva a cabo una campaña de aforos diferenciales en los ríos Guadiana y Azuer, con el objetivo objetivo de evaluar la descarga de las aguas subterráneas al cauce del Guadiana.

Las mediciones de caudal de "entrada" se realizan en el río Guadiana a la altura del molino de La Máquina, y en el Azuer, antes de su confluencia con el
Guadiana. La medida del caudal de "salida" se realiza en el río Guadiana, a la altura del molino de El Nuevo. La diferencia de caudal entre los puntos de "salida" y "entrada", supone la aportación subterránea drenada en el tramo comprendido entre ambos molinos (Figura 9).

El caudal de drenaje en los ríos y secciones mencionados, y el aporte de agua subterránea en esa zona, resultan nulos a partir de junio de 2017. Con el objeto de mantener el seguimiento del drenaje subterráneo en el entorno de Los Ojos del Guadiana, en enero de 2018 se comienza a controlar el caudal del río Guadiana en el molino de Griñón (Figura 9). Mientras que en las secciones de El Nuevo y La Máquina, a fecha de noviembre de 2018, el caudal de drenaje permanece nulo, en el Molino de Griñón se ha medido un caudal creciente desde enero de 2018 hasta alcanzar los $418 \mathrm{l} / \mathrm{s}$ a finales de mayo de 2018. Posteriormente este caudal desciende hasta hacerse nulo desde agosto a noviembre de 2018. La evolución del caudal en este punto responde, principalmente, a las precipitaciones de la primavera de 2018.

\section{Variación del almacenamiento subterráneo}

Una estimación, grosso modo, de la variación del volumen de agua almacenado en el ámbito territorial de las tres masas centrales de la CAG obtiene que, en el período 1980-2018, tomando como referencia la situación hidrogeológica en periodo de aguas altas, podría ha- 
berse producido un vaciado de unos $1.125 \mathrm{hm}^{3}$, equivalente a un descenso medio de $9 \mathrm{~m}$, para el conjunto de los 38 años considerados, en las tres MASb centrales.

El volumen medio de reservas por cada metro de acuífero se estima en $125 \mathrm{hm} / \mathrm{m}$, valor deducido de considerar una superficie permeable de $5.000 \mathrm{~km}^{2} \mathrm{y}$ un coeficiente de almacenamiento de 0,025 (Mejías M. et al., 2012). En la figura 10 se presenta la evolución de la variación del volumen de agua almacenado, tomando como referencia el estado del acuífero en el año 1980. Entre el momento de máximo vaciado de reservas de las masas centrales, identificado en el periodo de aguas altas de 1996, y la situación en aguas altas de 2018 , el volumen almacenado se ha incrementado en $2.625 \mathrm{hm}^{3}$ en el subsuelo del sector central de la CAG (Figura 10).

\section{Evolución hidrogeológica de la MASb 041.010 Campo de Montiel}

La MASb de Campo de Montiel se caracteriza por presentar un régimen de acuífero libre, y un patrón del flujo subterráneo heterogéneamente distribuido, condicionado por la presencia y dirección de fracturas, y de la existencia de zonas o niveles karstificados. Presenta escasa capacidad de almacenamiento y notables oscilaciones piezométricas ligadas a los eventos de precipitación puntuales.

La lluvia es la principal fuente de recarga de la MASb, y la descarga se produce, principalmente, a través de los manantiales que se sitúan en los márgenes oeste y sur, y en el interior de la misma, dando origen y/o aportando caudal a los ríos. La mayor parte del agua recargada en la MASb Campo de Montiel acaba saliendo hacia el sector central de la CAG, mayorita- riamente hacia la MASb Mancha Occidental II, bien en superficie a través de manantiales o cauces superficiales, o bien por transferencia subterránea, con un límite máximo de transferencia en torno a los 45-50 hm³/año (Martínez-Cortina L., 2008).

\section{Evolución piezométrica 1980-2018}

La evolución piezométrica en esta MASb se analiza mediante los datos registrados en 7 piezómetros seleccionados como representativos, ubicados en los diferentes sectores que agrupan zonas de comportamiento piezométrico "uniforme" (Tabla 5).

Desde el punto de vista de su piezometría (cotas y dirección de flujo), la MASb del Campo de Montiel no ha sufrido alteraciones drásticas con respecto a su funcionamiento en régimen natural. Las importantes oscilaciones de los niveles piezométricos observables obedecen más a las secuencias pluviométricas que a las extracciones de agua del acuífero, si bien en periodos secos se acentúa temporalmente la afección piezométrica en la zona central de la MASb debido a los bombeos (Martínez-Cortina L., 2008; Montero E., 2000).

Para su evaluación piezométrica, se compara la situación entre el último periodo de aguas altas del que se disponen datos (marzo de 2018), con los datos de marzo de 1980, 2009, 2014 y de 2017.

Con respecto a los niveles medidos en el año1980, se obtiene un ascenso promedio de 0,03 $\mathrm{m}$, si bien el comportamiento es diferente si tenemos en cuenta los sectores considerados (Tabla 5). En el sector norte-noroeste se registra un descenso de 1,0 y $0,7 \mathrm{~m}$ en los dos piezómetros representativos de esta zona. En la zona nororiental, representada por el piezómetro 223030001, se contabiliza un ascenso de nivel de 0,2

\begin{tabular}{|c|c|c|c|c|c|c|c|c|c|c|c|c|}
\hline \multicolumn{13}{|c|}{ PIEZÓMETROS REPRESENTATIVOS DE LA MASb CAMPO DE MONTIEL } \\
\hline No Registro & MASb & $\begin{array}{c}\text { Cota } \\
m \text { s.n.m. }\end{array}$ & \begin{tabular}{|c} 
Prof. \\
$m$
\end{tabular} & $\begin{array}{l}P . N . P . \\
\text { mar-80 }\end{array}$ & \begin{tabular}{|l|} 
P.N.P. \\
mar-09 \\
\end{tabular} & $\begin{array}{l}\text { P.N.P. } \\
\text { mar-14 }\end{array}$ & $\begin{array}{l}\text { P.N.P. } \\
\text { mar-17 }\end{array}$ & $\begin{array}{l}\text { P.N.P. } \\
\text { mar-18 }\end{array}$ & $\begin{array}{c}\text { Dif. } 1980- \\
\text { mar-18 }\end{array}$ & \begin{tabular}{|l|} 
Dif. Marzo \\
2009-2018
\end{tabular} & \begin{tabular}{|l|} 
Dif. Marzo \\
20014-2018
\end{tabular} & \begin{tabular}{|l|} 
Dif. Marzo \\
2017-2018
\end{tabular} \\
\hline 213060003 & \multirow{2}{*}{$\begin{array}{c}\text { Norte- } \\
\text { Noroeste }\end{array}$} & 799 & 118 & 32,44 & 33,4 & 31,33 & 33,48 & 33,42 & $-0,98$ & $-0,02$ & $-2,09$ & 0,06 \\
\hline 213130010 & & 840 & 50 & 30,08 & Seco & & & 30,78 & $-0,70$ & & & \\
\hline 223030001 & 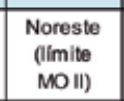 & 822 & 67 & 57,45 & 30,22 (Nov, 09) & 35,28 & 57,41 & 57,21 & 0,24 & $-6,99$ & $-21,93$ & 0.20 \\
\hline 223120001 & \multirow{3}{*}{ Central } & 915 & 50 & 20,12 & 11,84 & 8.23 & 20,87 & 18,65 & 1,47 & $-6,81$ & $-10,42$ & 2,22 \\
\hline 223150014 & & 880 & & & 40,64 & & 39,08 & 38,21 & & 2,43 & & 0,87 \\
\hline 223210013 & & 945 & 50 & 44,7 & 39,34 & 37,65 & 45,69 & & & & & \\
\hline 223240023 & Suroriental & 1.040 & 69 & 62,28 & 56,89 & 52,69 & 62,94 & 62,15 & 0,13 & $-5,26$ & $-9,46$ & 0,79 \\
\hline & Medidas & hidrc & gico & $/ / 18$ & & & & MEDIA & 0,0 & $-3,3$ & $-11,0$ & 0,8 \\
\hline
\end{tabular}

Tabla 5. Profundidad de nivel piezométrico en los piezómetros representativos de la masa de agua subterránea MASb Campo de Montiel y diferencias entre estas (en metros).

Table 5. Piezometric level depth in the representative piezometers of the Campo de Montiel GWB. 
m y, en la zona central (directamente relacionada con la situación hidrológica de las Lagunas de Ruidera, e históricamente representada por el comportamiento del piezómetro 223120001), se registra un ascenso de $1,5 \mathrm{~m}$ con respecto a la medida de marzo de 1980. En el sector suroriental, representado por el piezómetro 223240023, se identifica un ascenso de 0,1 m entre la medida de marzo de 1980 y la del mismo mes de 2018. Se puede concluir, por tanto, que cada sector presenta un comportamiento hidrogeológico diferente y que este responde, básicamente, a la proximidad en el tiempo entre la medida de nivel piezométrico con respecto al evento de precipitación, además de la intensidad del episodio lluvioso.

La comparación entre las medidas del año 2009 (escenario del último mínimo piezométrico relevante) y las de 2018, refleja un descenso promedio de 3,3 $\mathrm{m}$, pero a afectos de zonificación interna de la MASb, muy heterogénea en cuanto a los valores mostrados ( $7 \mathrm{~m}$ de descenso en el sector noreste por 2,4 de ascenso en el sector central).
La comparación de niveles en piezómetros representativos entre los años 2014-2018 muestra un descenso promedio de $11,0 \mathrm{~m}$ para el conjunto de la MASb de Campo de Montiel. A nivel interno, en los diferentes sectores de la MASb, este descenso varía entre de los 2,1 $\mathrm{m}$ de descenso en el sector noroccidental, hasta los $21,9 \mathrm{~m}$ en el sector noreste.

Finalmente, entre el periodo de aguas altas de 2017 y 2018 se produce un ascenso de nivel piezométrico promedio de $0,8 \mathrm{~m}$, ascenso que se produce en todos los piezómetros representativos de la MASb independientemente de la zona controlada, si bien en el piezómetro 232120001 del sector central el ascenso se amplifica $(2,2 \mathrm{~m}$ de ascenso, mientras que en el resto de piezómetros en ningún caso se llega a $1 \mathrm{~m}$ ). El comportamiento piezométrico ascendente contrasta con lo que ocurre en el sector central de la CAG en el que, para el mismo periodo, se registró un descenso promedio de nivel de más de 2 metros. Esta diferencia evidencia de nuevo la rápida respuesta de este acuífero a las precipitaciones del invierno y primavera de 2018.

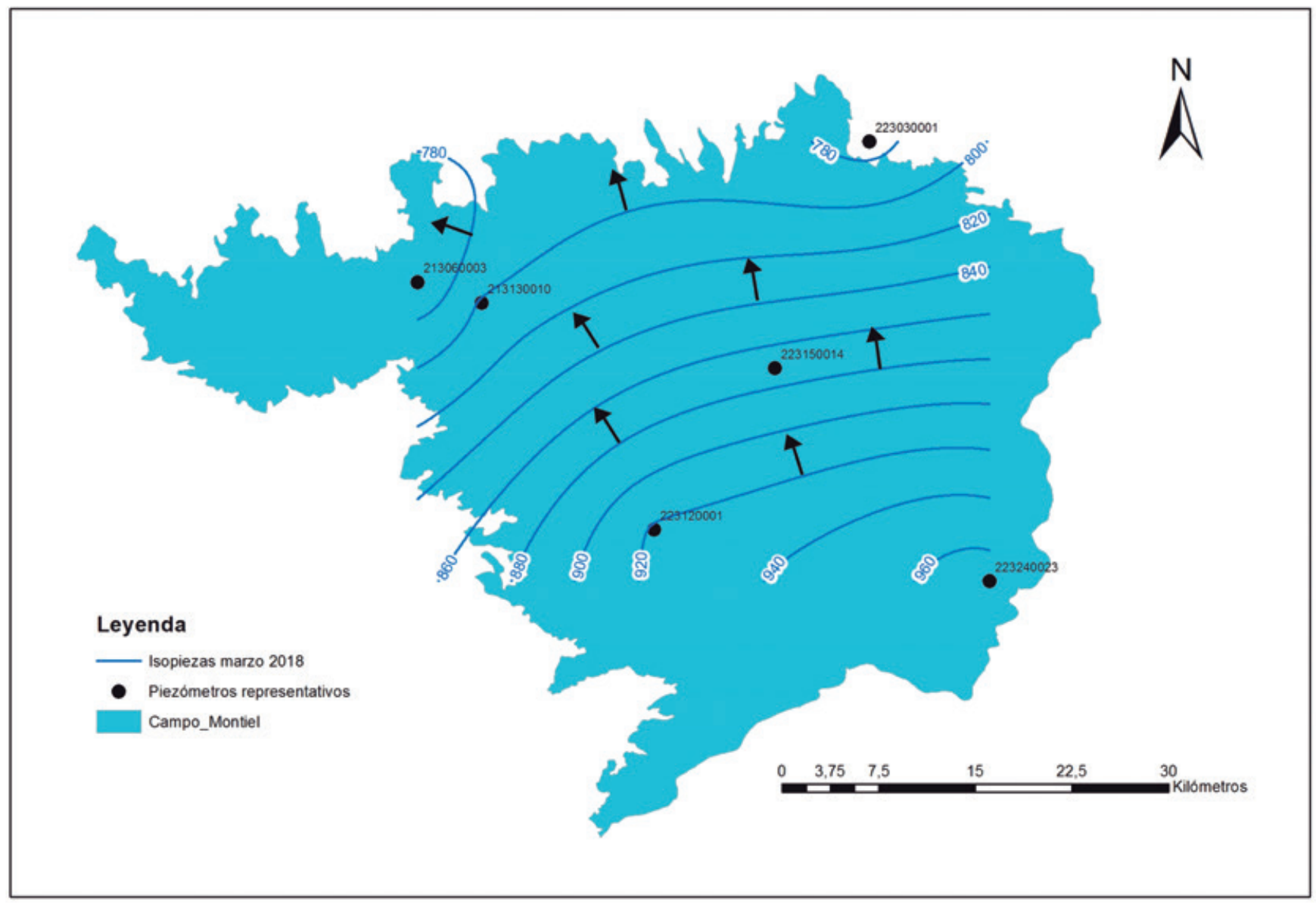

Figura 11. Mapa de isopiezas (en m s.n.m) de la MASb Campo de Montiel, marzo de 2018.

Figure 11. Piezometric contour lines (m a.s.I.) in the Campo de Montiel GWB, March 2018. 
En resumen, el comportamiento piezométrico de la MASb Campo de Montiel contrasta con el del sector central de la CAG dada su naturaleza kárstica aflorante directamente en superficie. La presencia de fracturas y niveles karstificados crea también diferencias a nivel interno de la MASb. En general, las entradas y salidas de agua se producen de forma rápida, a través de la red de fracturación y/o karstificación, y su capacidad de almacenamiento es muy limitada. En consecuencia, como característica principal de esta MASb, cabe indicar que los niveles piezométricos sufren fuertes oscilaciones en función del régimen de precipitaciones y la capacidad de regulación es escasa.

La precipitación del año hidrológico 2017/18 registrada en la estación de Ruidera ha sido de $477,1 \mathrm{~mm}$, superior a la del año anterior $(434,1 \mathrm{~mm}$ en 2016/17) y un $7 \%$ superior a la media anual $(444,9 \mathrm{~mm})$. El ascenso piezométrico identificado para este periodo es lógico en un acuífero de las características anteriores y las condiciones climatológicas dadas. En esta MASb la magnitud de los ascensos/descensos no es significativa, puesto que su valor depende de la cercanía de la medida piezométrica al último evento de precipitación inmediatamente anterior.

\section{Mapa de isopiezas y flujo subterráneo}

El mapa de isopiezas de la MASb 041.010 Campo de Montiel se ha elaborado a partir de los datos de la red de seguimiento piezométrico controlada por el IGME. EI acuífero jurásico de la MASb Campo de Montiel, como ya se ha dicho, presenta porosidad por fracturación y/o karstificación, por lo que, por definición, el flujo se concentra a favor de conductos y fracturas, mostrando un patrón de circulación muy heterogéneo.

El mapa de isopiezas aquí mostrado (Figura 11) se ha elaborado exclusivamente a partir de las medidas piezométricas tomadas por el IGME en la red de control en marzo de 2018. El mapa de isopiezas resultante es una simplificación de la piezometría real, en el que se muestra la dirección de flujo preferente del conjunto de la MASb, con un gradiente hidráulico aproximado de $5 \cdot 10^{-3}$.

El esquema de flujo subterráneo no se ha alterado significativamente desde su estado asimilable al régimen natural hasta la actualidad. Los niveles piezométricos, como ya se ha dicho, fluctúan en función de la sucesión de periodos húmedos y secos, mientras que el flujo subterráneo mantiene un patrón de circulación invariable, de sur a norte en el conjunto de la MASb. No se muestran aquí las inflexiones locales de la piezometría hacia sus márgenes de descarga este, sur y oeste ni hacia el río Guadiana Alto, por no disponer de medidas propias.
La recarga se produce en toda la superficie de la MASb, pero el flujo se desplaza, mayoritariamente, desde las zonas más altas, situadas al sur, hacia la Llanura Manchega en su extremo norte. La descarga se produce a favor de manantiales y cauces superficiales, y por transferencia subterránea hacia la MASb Mancha Occidental II.

\section{Evolución hidrogeológica de la MASb Sierra de Altomira}

En la MASb Sierra de Altomira se diferencian tres acuíferos de muro a techo, uno primero asociado a los materiales carbonatados jurásicos, un segundo en los materiales carbonatados cretácicos, y un último que engloba los niveles permeables terciarios y cuaternarios. Tanto por calidad de sus aguas, como por la cantidad y el uso que se hace de ellas, los niveles de mayor interés son los pertenecientes a los acuíferos jurásico y cretácico. No obstante, se incluye también en este seguimiento puntos que controlan niveles terciarios, además de para contrastar su evolución con respecto a la de los acuíferos mesozoicos, porque constituyen acuíferos aprovechables localmente.

La relación hidrogeológica entre las diferentes unidades acuíferas es compleja, al igual que lo es la continuidad hidrogeológica de una misma unidad acuífera (jurásica o cretácica) a lo largo de la masa de agua. Con toda probabilidad, la MASb Sierra de Altomira se encuentra subdividida en diferentes bloques estructurales que reflejarían un efecto de compartimentación hidrogeológica (Díaz J.A. y Martínez, M., 2009; Díaz J.A. et al., 2011; Martínez, M y Díaz J.A., 2013; del Pozo J. et al., 2019). Los acuíferos terciarios se restringen a los niveles permeables que rellenan las cuencas interpuestas entre los afloramientos mesozoicos, por lo que su compartimentación resulta evidente. Establecer, por tanto, un conjunto de piezómetros representativos de la evolución de la MASb es especialmente complejo en el caso de Sierra de Altomira.

\section{Evolución piezométrica 1982-2018}

Para el análisis de la evolución piezométrica de esta MASb se han seleccionado todos los piezómetros de observación adscritos a cada uno de los acuíferos con un registro histórico amplio y que cuenten con medidas periódicas en la actualidad. Se establecerá así la evolución piezométrica a partir de los registros de los periodos de aguas altas de los años 1982 (asimilable al estadio previo respecto al periodo de intenso aprovechamiento de las aguas subterráneas), 2009 (año del máximo descenso piezométrico), 2014 (año del 


\begin{tabular}{|c|c|c|c|c|c|c|c|c|c|c|c|c|c|}
\hline \multirow{9}{*}{ 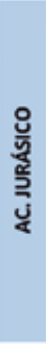 } & \multicolumn{13}{|c|}{ PIEZÓMETROS REPRESENTATIVOS DEL ACUIFFERO JURÁSICO DE LA MASb SIERRA DE ALTOMIRA } \\
\hline & \multirow{2}{*}{$\begin{array}{l}\text { No Registro } \\
\text { IGME }\end{array}$} & \multirow[b]{2}{*}{ Zona MASb } & \multirow{2}{*}{$\begin{array}{c}\text { Cota } \\
\text { m s.nm. }\end{array}$} & \multirow{2}{*}{$\begin{array}{c}\text { Prot. } \\
\text { m }\end{array}$} & \multicolumn{5}{|c|}{ P.NP. (m) } & \multicolumn{4}{|c|}{ Diferencia de nivel } \\
\hline & & & & & mar-82 & fob-09 & fob-14 & $\operatorname{mar}-17$ & mar-18 & $\begin{array}{l}\text { Feb 1982- } \\
\text { Mar 2018 }\end{array}$ & $\begin{array}{l}\text { Feb 2009- } \\
\text { Mar 2018 }\end{array}$ & $\begin{array}{l}\text { Feb 2014 } \\
\text { Mar 2018 }\end{array}$ & $\begin{array}{l}\text { Mar 2017- } \\
\text { Mar 2018 }\end{array}$ \\
\hline & 212680010 & Rama Almenara & 825 & 170 & 100,97 & sin dato & 110,84 & 112.26 & 112,18 & $-11,21$ & & $.1,34$ & 0,08 \\
\hline & 212730003 & & 718 & 160 & $\sin$ datos & $\sin$ datos & 62,7 & 67,15 & 71.25 & & & $-8,55$ & $-4,10$ \\
\hline & 212780002 & Los Hinojosos & 769 & 136 & 66.2 & 68.75 & 68.1 & 68,37 & 68.82 & $.2,62$ & -0.07 & $.0,72$ & $.0,45$ \\
\hline & 212820002 & $\begin{array}{c}\text { Campo de } \\
\text { criptana }\end{array}$ & 678 & 260 & 20,00 & 40,36 & 34,39 & 39.5 & 41,84 & $-21,84$ & $-1,48$ & $-7,45$ & $-2,34$ \\
\hline & 222620010 & $\begin{array}{c}\begin{array}{c}\text { Rama Villarejo } \\
\text { de Fuentos }\end{array} \\
\end{array}$ & 911 & 300 & $\sin$ dalos & $\sin$ datos & 105,12 & 114,3 & 115.87 & & & $-10,75$ & $-1,57$ \\
\hline & 222810007 & Extremosur & 726 & 235 & 44 & 60,93 & 50.28 & 52,08 & 55 & $-11,00$ & 5,93 & $-4,72$ & $-2,92$ \\
\hline
\end{tabular}

Variación Promedilo \begin{tabular}{|l|l|l|l|}
\hline$-11,7$ & 1,5 & $-5,6$ & $-1,9$ \\
\hline
\end{tabular}

\begin{tabular}{|c|c|c|c|c|c|c|c|c|c|c|c|c|c|}
\hline \multirow{11}{*}{ 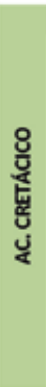 } & \multirow{3}{*}{\multicolumn{4}{|c|}{\begin{tabular}{|c|c|}
\multicolumn{2}{|c|}{ PIEZOMETROS } \\
Cota & Prof. \\
m s.nm. & m \\
\end{tabular}}} & PRESE & $\operatorname{COS} \mathrm{Dt}$ & IFEROC C & acot & $\mathrm{ASb}$ SI & DE ALTO & & & \\
\hline & & & & & \multicolumn{5}{|c|}{ P.N.P. (m) } & \multicolumn{4}{|c|}{ Diferencia de nivel } \\
\hline & & & & & leb-82 & fob-09 & feb-14 & $\operatorname{mar}-17$ & $\operatorname{mar}-18$ & $\begin{array}{l}\text { Fob 1982- } \\
\text { Mar 2018 }\end{array}$ & $\begin{array}{l}\text { Mar 2009- } \\
\text { Mar 2018 }\end{array}$ & $\begin{array}{l}\text { Pob 2014 } \\
\text { Mar 2018 }\end{array}$ & $\begin{array}{l}\text { Mar 2017- } \\
\text { Mar 2018 }\end{array}$ \\
\hline & 212820001 & \multirow{3}{*}{ Extremo sur } & 680 & 320 & $\sin$ datos & sin datos & 15,12 & 16,73 & 16,89 & & & $-1,77$ & $-0,16$ \\
\hline & 212830006 & & 680 & 290 & 15 & 37,29 & 35.38 & 37,72 & 36.54 & $-21,54$ & 0.75 & $-1,16$ & 1,18 \\
\hline & 212840009 & & 682 & 70 & $\sin$ datos & 21,59 & 14,14 & 16,53 & 17,13 & & 4,46 & $-2,99$ & $-0,60$ \\
\hline & 222410015 & Extremo notte & 990 & 252 & $\sin$ dalos & $\sin$ dalos & 164,12 & 166 & 171.24 & & & $-7,12$ & -5.24 \\
\hline & 222580012 & $\begin{array}{l}\text { Ant de Zafra de } \\
\text { Zancara }\end{array}$ & 832 & 15 & $\sin$ dalos & sin dalos & 5.85 & 5,73 & 5.62 & & & 0.23 & 0,11 \\
\hline & 222670019 & \multirow{2}{*}{$\begin{array}{l}\text { Rama Villarejo } \\
\text { de Fuentes }\end{array}$} & 857 & 110 & $\sin$ datos & sin datos & 11,58 & 7,61 & 7,63 & & & 3,95 & -0.02 \\
\hline & 222770003 & & 823 & 100 & $\sin$ datos & sin datos & 2,33 & 2,31 & 2.27 & & & 0,08 & 0,04 \\
\hline & 232720019 & $\begin{array}{l}\text { Ant do la } \\
\text { Almarcha }\end{array}$ & 918 & 194 & $\sin$ datos & 91.1 & 64.82 & 93.21 & 100.13 & & $-9,03$ & $-35,31$ & -6.92 \\
\hline
\end{tabular}

Variación Promedio \begin{tabular}{|c|c|c|c|}
\hline-21.5 & -1.3 & -5.5 & -1.5 \\
\hline
\end{tabular}

\begin{tabular}{|c|c|c|c|c|c|c|c|c|c|c|c|c|c|}
\hline \multirow{9}{*}{ 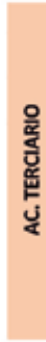 } & \multicolumn{13}{|c|}{ PIEZÓMETROS REPRESENTATIVOS DEL ACUIFERO TERCIARIO DE LA MASb SIERRA DE ALTOMIRA } \\
\hline & \multirow{2}{*}{$\begin{array}{l}\text { No Registro } \\
\text { IGME }\end{array}$} & \multirow{2}{*}{$\begin{array}{l}\text { Acuiftero que } \\
\text { captan }\end{array}$} & \multirow{2}{*}{$\begin{array}{c}\text { Cota } \\
\text { m s.nm. }\end{array}$} & \multirow{2}{*}{$\begin{array}{c}\text { Prot. } \\
\text { m }\end{array}$} & \multicolumn{5}{|c|}{ P.NP. (m) } & \multicolumn{4}{|c|}{ Dfferencia de nivel } \\
\hline & & & & & mar-82 & fob-09 & fob-14 & $\operatorname{mar}-17$ & mar-18 & $\begin{array}{l}\text { Fob 1982. } \\
\text { Mar 2018 }\end{array}$ & $\begin{array}{l}\text { Mar 2009- } \\
\text { Mar 2018 }\end{array}$ & $\begin{array}{l}\text { Fob 2014 } \\
\text { Mar } 2018\end{array}$ & $\begin{array}{l}\text { Mar 2017- } \\
\text { Mar 2018 }\end{array}$ \\
\hline & 212640004 & Terciario & 766 & 23 & 11,03 & $\sin$ datos & 6,94 & 10,9 & 11,67 & $-0,64$ & & $-4,73$ & $-0,77$ \\
\hline & 212770001 & Moceno & 698 & 300 & $\sin$ dalos & $\sin$ datos & 15.85 & 17,45 & 19,11 & & & $.3,26$ & $-1,66$ \\
\hline & 222410002 & $\begin{array}{l}\text { Terciario- } \\
\text { Cretacioo }\end{array}$ & 964 & 51 & 34 & $\sin$ datos & 28.51 & 28.7 & 27,72 & 6.28 & & 0.79 & 0,98 \\
\hline & 222610002 & Moceno inferior & 810 & 106 & 1.55 & sin datos & 2.1 & 2.6 & 2.68 & $-1,13$ & & $-0,58$ & -0.08 \\
\hline & 222620003 & $\begin{array}{l}\text { Moceno } \\
\text { superior }\end{array}$ & 900 & 7,1 & $\sin$ datos & sin datos & 5.7 & seco & 7,93 & & & $-2,23$ & \\
\hline & 232610002 & Terciaño & 835 & 80 & 17 & sin datos & 20,96 & 23,54 & 23,47 & $-6,47$ & & $-2,51$ & 0,07 \\
\hline & & las a & óggio & 18 & & & & Variac & amedio & $-0,5$ & & $-2,1$ & $-0,3$ \\
\hline
\end{tabular}

Tabla 6. Medidas de profundidad de nivel piezométrico en años concretos, y diferencias $(\mathrm{m})$ entre ellos en los piezómetros representativos de los acuíferos jurásico, cretácico y terciario en la MASb Sierra de Altomira.

Table 6: Piezometric depth in the representative piezometers of the Jurassic, cretaceous and tertiary aquifers in the Sierra de Altomira GWB.

último máximo piezométrico), y 2017 como dato representativo del año hidrológico previo.

En la red de control de la MASb Sierra de Altomira se diferencian, por un lado, los piezómetros que controlan los niveles jurásicos y, por otro, los que controIan los cretácicos. A priori, se consideran acuíferos independientes, separados por los depósitos detríticos y margosos de la formación Utrillas y la facies Weald (Cretácico inferior), a pesar de que en ciertas zonas del sector occidental esta diferenciación podría no existir (Martínez M. y Díaz J.A. 2013). Los piezómetros que controlan materiales terciarios se han incluido en un único grupo.

Para evaluar la evolución piezométrica de la MASb Sierra de Altomira se han seleccionado un total de 20 piezómetros agrupados por zonas estructurales dentro de la MASb Sierra de Altomira (Tabla 6). Del total de piezómetros seleccionados como representativos, 6 controlan el acuífero jurásico, 8 los niveles cretácicos y 6 piezómetros los niveles terciarios.

Dentro de una misma escama tectónica (Querol R., 1989), los acuíferos jurásico y cretácico presentan régimen libre en las zonas de afloramiento, pasando a confinado a medida que las formaciones se hunden bajo las cuencas terciarias. La amplitud de las oscilaciones piezométricas dependerá de la posición del piezómetro con respecto al sector aflorante de la formación, siendo más variable en las zonas topográficamente más elevadas, y más estable en los piezómetros que capten niveles más profundos. Entre los 
niveles terciarios se encuentran acuíferos libres y semiconfinados (Díaz, J.A. y Martínez, M., 2009).

El comportamiento mixto de los acuíferos mesozoicos, de acuífero de régimen libre en las zonas de afloramiento, y confinado en profundidad, confiere a la masa de agua subterránea, en general, una capacidad de regulación mayor que en la MASb de Campo de Montiel, pese a ser también acuíferos de tipo carbonatado cuyos materiales afloran parcialmente en superficie.

La lluvia es la fuente principal de recarga de la MASb, además de las pérdidas en ríos y los retornos de riego. La descarga de los acuíferos jurásico y cretácico se produce, fundamentalmente, hacia los cauces superficiales, pero también hacia los niveles terciarios suprayacentes, a través de manantiales en las zonas de contacto con niveles terciarios, y por transferencia subterránea hacia otras MASb (Mancha Occidental II y Rus-Valdelobos) en el límite sur, además de las extracciones. Por su parte, los niveles terciarios, además de por la lluvia y transferencias desde los ríos, pueden ser recargados en profundidad por aportes subterráneos desde los niveles mesozoicos subyacentes. La descarga se produce fundamentalmente hacia los cauces superficiales y por bombeos.

Desde el punto de vista de su comportamiento hidrológico, los acuíferos mesozoicos de Sierra de Altomira han sufrido un descenso moderado con respecto a sus niveles asimilables al régimen natural. Esta variación se debería, de forma directa, al incremento del volumen de extracciones que se produjo a partir de la década de los 80 del pasado siglo y al comienzo de un ciclo seco que contrasta con las décadas más húmedas anteriores.

\section{Acuífero jurásico}

La evolución piezométrica del acuífero jurásico se analiza mediante 6 piezómetros, ubicados todos ellos en la mitad occidental, ya que es en este sector donde los niveles jurásicos afloran en una gran extensión. Aquí el acuífero jurásico tiene una recarga importante, y se encuentra a una profundidad en la que sus recursos hídricos son susceptibles de aprovechamiento.

En relación con los niveles medidos en el año 1982, la comparación con los de 2018 refleja un descenso promedio de $11,7 \mathrm{~m}$, aunque con valores muy variables en los piezómetros considerados (Tabla 6). Teniendo en cuenta la posible compartimentación interna de la MASb, la determinación de un comportamiento piezométrico unitario es poco realista. Sin embargo, resulta evidente que, independientemente de la sectorización de la MASb, desde el comienzo de la década de los 80 hasta el año 2018, el acuífero jurásico ha registrado un descenso más o menos generalizado, con un valor promedio de $10 \mathrm{~m}$.

La comparación de los niveles de marzo de 2018 con los niveles de 2009 refleja un ascenso promedio de 1,5 m. El dato es coherente con la evolución piezométrica esperable entre los dos años comparados. No obstante, este aspecto debe ser valorado es su justa medida, dado que se calcula a partir de los niveles registrados únicamente en 3 piezómetros.

La comparativa de niveles entre los años 20142018 en el acuífero jurásico muestra un descenso generalizado, con un promedio de $5,6 \mathrm{~m}$, si bien destaca de nuevo la gran variabilidad dependiendo del sector controlado $(0,7 \mathrm{~m}$ a $10,7 \mathrm{~m}$ de descenso).

Entre el periodo de aguas altas de 2017 y 2018 se produce un descenso de nivel piezométrico promedio de 1,9 m en toda la MASb. Este descenso presenta magnitudes diferentes dependiendo de la zona (Tabla 6). Este comportamiento está en sintonía con lo que ocurre en el sector central de la CAG, y evidencia una respuesta piezométrica a las precipitaciones con mayor componente inercial que el acuífero kárstico de Campo de Montiel.

El año hidrológico 2017/18 se clasifica como húmedo, con un valor de precipitación anual de $670 \mathrm{~mm}$ en la estación 4075 de Villares del Saz. Este valor supera en un $30 \%$ la media anual para esta estación $(466,1 \mathrm{~mm})$. El descenso piezométrico en el periodo marzo 2017-marzo 2018 evidencia que las precipitaciones del último año hidrológico no han tenido reflejo en la piezometría del acuífero jurásico de esta MASb, a fecha de marzo de 2018.

El comportamiento piezométrico tan dispar entre unas zonas y otras de la MASb, observable en todas las comparaciones analizadas, sustenta la idea de compartimentación regional del acuífero jurásico (Díaz J.A. y Martínez M., 2009; Díaz J.A. et al., 2011; Martínez M. y Díaz J.A., 2013; del Pozo J. et al., 2019). También influye en este aspecto el diferente grado de conexión del cada piezómetro con el acuífero regional.

\section{Acuífero cretácico}

La evolución piezométrica del acuífero cretácico se analiza mediante 8 piezómetros, ubicados a lo largo de toda la masa de agua, a excepción del margen occidental, en donde los niveles cretácicos son poco potentes o se encuentran ausentes.

En la comparativa de los niveles medidos en 2018 con respecto a los del año 1982 (Tabla 6), se obtiene un descenso promedio de 21,54 m. Este valor cuenta con una escasa representatividad al ser resultado de la comparación en un solo piezómetro, sin embargo su significado es coherente con el descenso espera- 


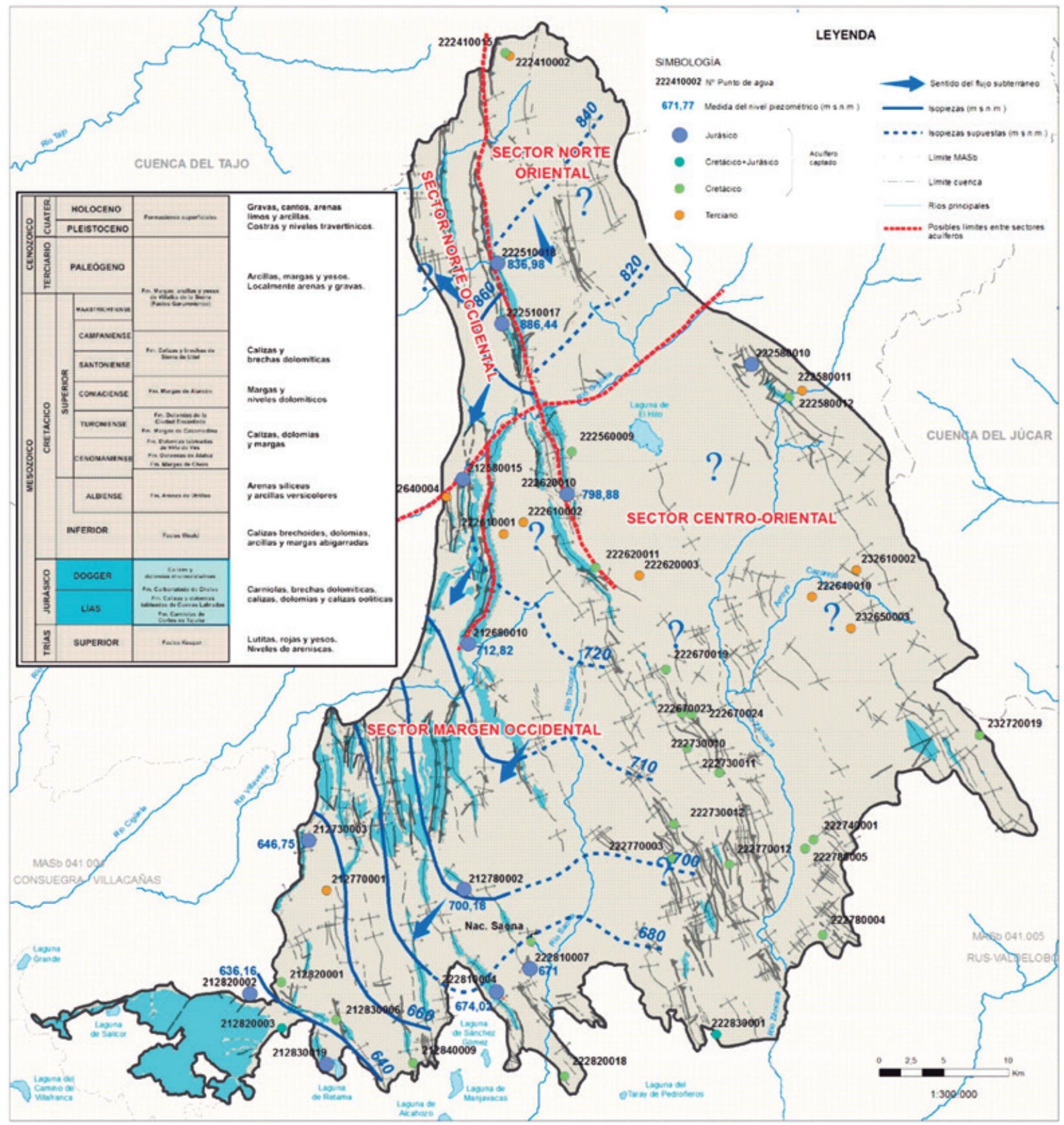

Figura 12. Mapa de isopiezas de los niveles jurásicos correspondiente al periodo de marzo de 2018 (Domínguez et al., 2018).

Figure 12. Piezometric contour lines of the Jurassic aquifer in the Sierra de Altomira GWB, March 2018 (Domínguez et al., 2018).

ble en la comparación piezométrica de los años anteriores para este acuífero.

La comparación de 2018 con los niveles de 2009 muestra un descenso promedio de $1,27 \mathrm{~m}$, si bien este valor está muy condicionado por el descenso sufrido en un único piezómetro (9 metros en el 232720019) mientras que se produce un ascenso en los otros dos piezómetros con datos. De nuevo, se observa una notable variabilidad regional en la evolución piezométrica.

En el periodo 2014-2018 resulta más evidente, si cabe, la variabilidad espacial del comportamiento piezométrico. Con un descenso promedio de 5,51 m para el conjunto de la MASb, los valores se encuentran 


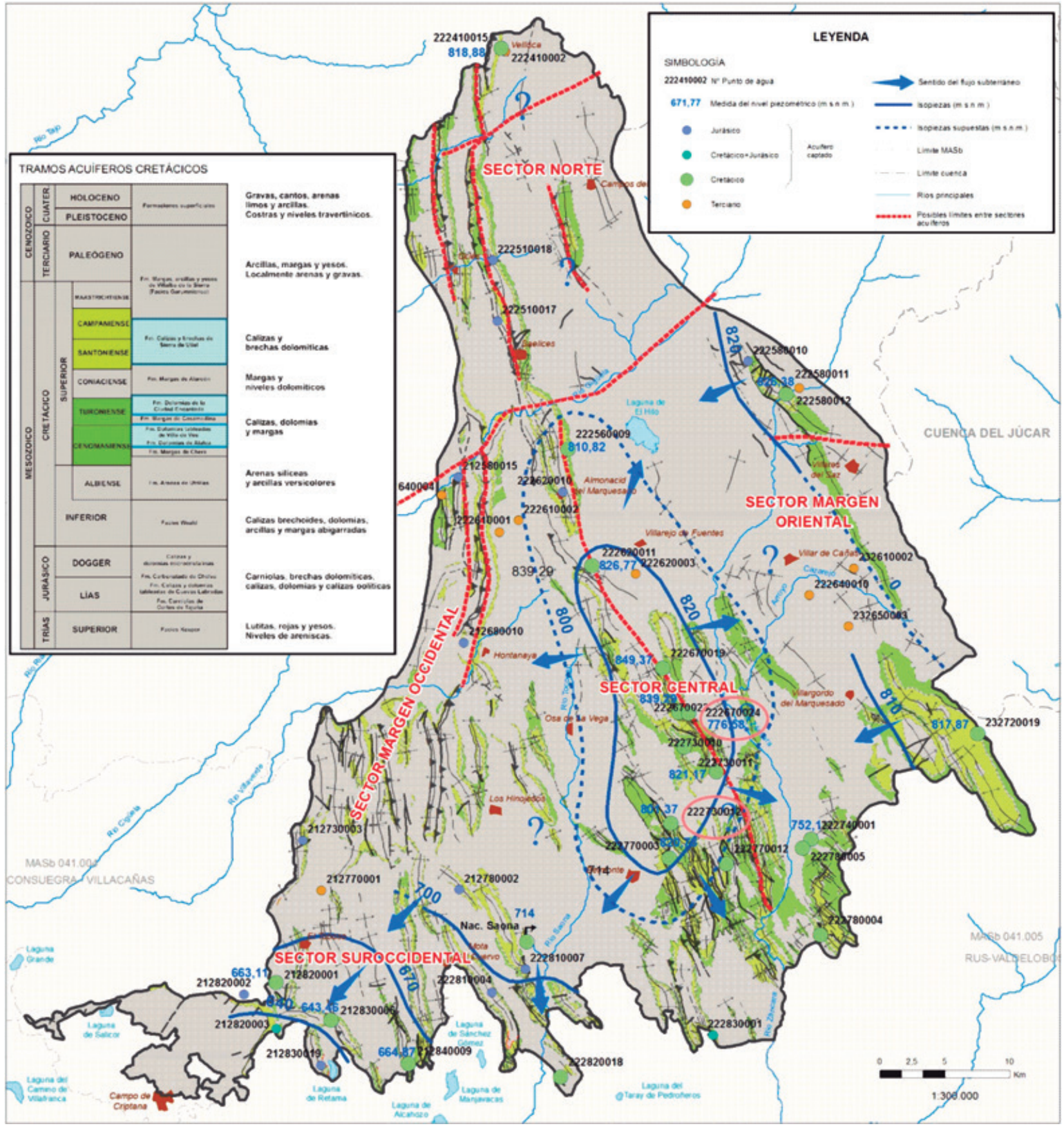

Figura 13. Mapa de isopiezas del acuífero cretácico correspondiente al periodo de marzo de 2018 (Domínguez J.A. et al., 2018).

Figure 13. Piezometric contour lines of the Cretaceous aquifer in the Sierra de Altomira GWB, March 2018 (Domínguez J.A. et al., 2018).

incluidos en la horquilla variable entre los $35,3 \mathrm{~m}$ de descenso y 3,9 $\mathrm{m}$ de ascenso.

Entre el periodo de aguas altas de 2017 y 2018 se produce un descenso de nivel piezométrico de 1,45 $\mathrm{m}$ como valor promedio de toda la MASb, variable entre los 6,92 $\mathrm{m}$ de descenso y 1,18 $\mathrm{m}$ ascendentes. El descenso observado en los piezómetros en el acuí- fero cretácico no refleja las importantes precipitaciones del año hidrológico 2017/18. Al igual que ocurre en el acuífero jurásico, y también en el sector central de la CAG, este acuífero presenta una respuesta retardada a los eventos de precipitación.

El comportamiento piezométrico diferente entre unas zonas y otras, como en el caso anterior, es in- 
dicativo de la compartimentación del acuífero, y del diferente grado de conexión del cada piezómetro con el acuífero regional.

\section{Acuífero terciario}

La evolución piezométrica del acuífero terciario se analiza mediante 6 piezómetros, distribuidos en las diferentes cuencas terciarias. En general, las variaciones de nivel identificadas son de menor magnitud que en los niveles mesozoicos. Por otro lado, las cuencas terciarias en esta MASb se encuentran intercaladas entre los afloramientos mesozoicos lineales, haciéndolas independientes entre sí.

La comparación de las medidas de marzo de 1982 y 2018 (Tabla 6), refleja un descenso promedio de $0,5 \mathrm{~m}$. Este valor es significativamente menor que la diferencia observada en los acuíferos jurásico y cretácico para los mismos años. Igual que en los casos anteriores, destaca la diferencia de valores (variable entre 6,5 m de descenso a 6,3 de ascenso). No existen medidas en los piezómetros considerados para el año 2009.

La comparación de niveles entre las medidas de marzo de los años 2014-2018 muestra un promedio de $2,1 \mathrm{~m}$ de descenso piezométrico, descenso prácticamente generalizado salvo en un caso $(0,8 \mathrm{~m}$ ascendentes en el piezómetro 222410002). Este comportamiento es coherente con el periodo climático seco 2014-2017 que representa.

Entre el periodo de aguas altas de 2017 y 2018 se produce un descenso promedio de nivel piezométrico de $0,3 \mathrm{~m}$, valor significativamente menor que los producidos en los acuíferos mesozoicos. El comportamiento vuelve a ser diferente en función de la zona, con una horquilla variable entre 1,7 $\mathrm{m}$ de descenso 1,0 $\mathrm{m}$ de ascenso. El descenso general en los niveles terciarios no refleja las precipitaciones del año hidrológico 2017/18, salvo en casos puntuales.

\section{Isopiezas y flujo subterráneo}

La compartimentación de los acuíferos jurásico y cretácico dentro de la MASb Sierra de Altomira ha sido tratada recientemente en del Pozo J. et al. (2019), además de en otros trabajos anteriores entre los que destacan Díaz J.A. y Martínez M. (2009), Díaz J.A. et al. (2011) o Martínez M. y Díaz J.A. (2013). En todos ellos se concluye que existe una compartimentación estructural en la MASb Sierra de Altomira que afecta a la dinámica hidrogeológica de los diferentes acuíferos presentes. En este trabajo se opta por dar continuidad a la representación de los mapas de isopiezas de los acuíferos jurásico y cretácico presentados, en su versión más actualizada, en Domínguez et al. (2018). La elaboración de mapas de isopiezas acordes con los últimos avances respecto a la compartimentación estructural de la MASb se encuentra en fase de elaboración a fecha de redacción de este artículo.

\section{Isopiezas del acuífero jurásico de la MASb Sierra de Altomira: marzo de 2018}

No se conocen con detalle las condiciones de la piezometría de los niveles jurásicos asimilables al régimen natural. La comparación de los niveles piezométricos históricos y actuales indican que se ha producido un descenso importante de niveles en las décadas de intensa explotación de finales del siglo $X X$ y comienzos del XXI. Sin embargo, se considera que este descenso no habría alterado, en gran medida, las direcciones de flujo dominantes, salvo de forma puntual y local.

En la figura 12 se presenta el mapa de isopiezas del acuífero jurásico (Domínguez J.A. et al., 2018). A modo de resumen, cabe afirmar que la mitad norte de la MASb presentaría una compartimentación más efectiva, mientras que, en la mitad sur, el acuífero jurásico tendría una mayor continuidad espacial. Se establece en la zona suroeste una dirección de flujo en sentido noreste-suroeste, hacia la MASb Mancha Occidental II y Rus-Valdelobos principalmente y, en menor medida, hacia la de Consuegra-Villacañas.

\section{Isopiezas del acuífero cretácico de la MASb Sierra de Altomira: marzo de 2018}

El mapa piezométrico de los niveles cretácicos se elabora a partir de las medidas tomadas en la red de seguimiento del IGME en marzo de 2018 (Figura 13).

En el mapa de isopiezas de la figura 13 (Domínguez J.A. et al., 2018) se refleja, igual que en acuífero jurásico, una compartimentación efectiva en la mitad septentrional de la MASb. En la mitad sur, por el contrario, la continuidad del acuífero cretácico sería mayor. En este sector, la piezometría describe un flujo subterráneo de forma radial, desde el sector central más elevado hacia sus márgenes. En el extremo suroccidental, la continuidad hidráulica de los niveles permite determinar una dirección de flujo hacia la MASb Mancha Occidental II.

\section{Conclusiones}

Desde el punto de vista climatológico, para el periodo 1980-2018, la serie definida a partir de las diferentes estaciones, describe prolongados ciclos secos entre 
los que se intercalan periodos húmedos, de intensidad variable, y generalmente de una duración menor. Destacan en este intervalo los ciclos secos 1980-1995, 1999-2009 y 2014-2017, y los húmedos 1996-1998 y 2009-2014.

El año hidrológico 2017/18 se clasifica como húmedo a nivel general en toda la CAG, y rompe con la tendencia seca anterior conformada por cuatro años hidrológicos secos.

La evolución piezométrica en el conjunto del sector central de la CAG (MASb Mancha Occidental I, Mancha Occidental II y Rus-Valdelobos) sigue una evolución, a priori, coherente con la secuencia de precipitación definida en el periodo 1980-2018. Un estudio más detallado en el que se comparan las medidas piezométricas en años concretos (hitos piezométricos), refleja un comportamiento piezométrico inercial en estas masas con respecto a los periodos lluviosos y secos. Esta componente inercial es mayor hacia el oeste, hacia la zona de descarga subterránea del sistema. De esta manera, la MASb Mancha Occidental I tiene una mayor capacidad de regulación (comportamiento más inercial) que las MASb mancha Occidental Il y Rus-Valdelobos, situadas aguas arriba en la dirección del flujo subterráneo.

En general, en el sector central de la CAG se observa un importante descenso piezométrico en comparación con las medidas de 1980, recuperado parcialmente a continuación del periodo húmedo 2009-2014. A partir de este último año se produce un nuevo proceso de descenso de niveles hasta el año 2018. Las Iluvias del último año hidrogeológico, clasificado como húmedo, no han tenido reflejo en la piezometría general de la CAG a fecha de marzo de 2018.

El mapa de isopiezas de 2018 muestra una dirección del flujo subterráneo este-oeste, en sentido oeste, similar a la dirección establecida para el estado natural. Este patrón de flujo, restablecido a partir del año 2012, se mantiene hasta el 2018. El drenaje natural a través de Los Ojos del Guadiana, resurgido de nuevo en el año 2012 con caudal significativamente menor, se ha reducido progresivamente hasta desaparecer de nuevo el año 2017.

La MASb de Campo de Montiel no ha sufrido alteraciones drásticas en cuanto a su piezometría en relación con su comportamiento en régimen no alterado, sin embargo, tras los ciclos de sequía prolongada la piezometría de la MASb acaba viéndose afectada. La evolución piezométrica de esta MASb se relaciona, en mayor medida, con los eventos de precipitación y secuencias pluviométricas concretas. Las isopiezas de marzo de 2018 muestran un patrón de circulación de sur a norte, similar al considerado para un escenario no alterado o natural.
En la MASb Sierra de Altomira se observan notables diferencias de comportamiento piezométrico en función del sector considerado, para un mismo periodo de tiempo. Este aspecto evidencia un funcionamiento hidrogeológico dispar para el conjunto de la MASb, justificado a partir de la compartimentación interna de las unidades acuíferas que la componen (acuíferos jurásico, cretácico y terciario). En general, se observa un descenso piezométrico moderado, en comparación con el estado natural, y recuperado parcialmente tras el periodo húmedo 2009-2014. El ciclo seco posterior implica un nuevo descenso de niveles hasta el año 2018. Las Iluvias del último año hidrológico aún no se han reflejado en la piezometría de los acuíferos mesozoicos, y lo hacen mínimamente lo hace en el terciario.

\section{Referencias}

Álvaro, M., Apalategui, O., Baena, J., Balcells, R., Barnolas, A., Barrera, J.L., Bellido, F., Cueto, L.A., Díaz de Neira, A., Elízaga, E., Fernández-Gianotti, J.R., Ferreiro, E., Gabaldón, V., García-Sansegundo, J., Gómez, J. A., Heredia, N., Hernández-Urroz, J., Hernández-Samaniego, A., Lendínez, A., Leyva, F., López-Olmedo, F.L., Lorenzo, S., Martín, L., Martín, D., Martín-Serrano, A., Matas, J., Monteserín, V., Nozal, F., Olive, A., Ortega, E., Piles, E., Ramírez, J.I., Robador, A., Roldán, F., Rodríguez, L.R., Ruíz, P., Ruiz, M.T., Sánchez-Carretero, R., Teixell, A. 1995. Mapa Geológico de la Península Ibérica, Baleares y Canarias a escala 1:1.000.000, edición 1995.

Del Pozo, J. y Mejías, M. 2017. Los Ojos del Guadiana y del Gigüela: el resurgir de una masa de agua subterránea declarada "en riesgo". Boletín Geológico y Minero, 128 (4): 885-911.

Del Pozo, J., Mejías, M. y Domínguez, J.A. 2019. Propuesta de compartimentación estructural en la MASb 041.001 Sierra de Altomira: implicaciones hidrogeológicas. Boletín Geológico y Minero, 130 (2):317-340.

Díaz J.A. y Martínez, M. 2009. Mejora del conocimiento en las MASb. Sierra de Altomira (040.001) y Rus-Valdelobos (040.005). Informe Inédito. Convenio de colaboración entre el IGME y la CHG. Centro de Documentación del IGME. Madrid. 187 pp + 14 mapas.

Díaz, J.A., Martínez M.; de la Losa, A. (2011). Actualización del conocimiento hidrogeológico de la masa de agua subterránea Sierra de Altomira (041.001). Convenio IGME-Diputación Provincial de Cuenca. Centro de Documentación del IGME, Madrid, 127 págs. + anejos. Informe inédito.

Domínguez, J.A., Vega, L., García, N., Mejías, M., Ochando, R. y del Pozo, J. 2018. Estudio piezométrico. Campaña de medida en aguas altas (marzo de 2018) en la MASb "Sierra de Altomira (041.001)" Convenio específico de 
colaboración entre la Comunidad de Regantes de Aguas Subterráneas de la Sierra de Altomira y el IGME, para el apoyo técnico en infraestructura hidrogeológica y aguas subterráneas. 2016-2018. Documento interno, 34 págs. + anejos.

IGME. 1979. Plan Nacional de Investigación de Aguas Subterráneas (PNIAS): Proyecto de investigación hidrogeológica de la cuenca alta y media del Guadiana. Informe final (Sistema 19: Sierra de Altomira. Sistema 20: de la Mancha de Toledo. Sistema 22: Cuenca del río Bullaque. Sistema 23: Llanura Manchega. Sistema 24: Campo de Montiel. Centro de Documentación del IGME, Madrid, 119 págs. +3 planos.

López Geta, J.A., Fabregat, V. y Olivares , J.F. 1989.. 1989. Sistema acuífero $n^{\circ}$ 23. Mancha Occidental. Serie: manuales de utilización de acuíferos. Instituto Tecnológico y Geológico de Madrid. Madrid.

López Gutiérrez, J., Plata J.L. y Mejías, M. 2013. Caracterización de la divisoria hidrogeológica Guadiana-Júcar en la Llanura Manchega mediante técnicas geológicas geofísicas. Boletín Geológico y Minero. 124 (3) 381-404.

Martínez-Cortina, L. 2008. Marco hidrológico del Campo de Montiel en el contexto de un modelo de gestión participativa de una masa de aguas subterráneas. Convenio de colaboración entre el Instituto Geológico y Minero de España (IGME) y la Confederación Hidrológica del Guadiana (CHG). Centro de Documentación del IGME, Madrid, 40 págs. Informe inédito.

Martínez-Cortina, L., Mejías, M., Díaz, J.A., Morales, R. y Ruíz, J.M. 2011. Cuantificación de recursos hídricos subterráneos en la cuenca alta del Guadiana. Consideraciones respecto a las definiciones de recursos renovables y disponibles. Boletín Geológico y Minero, 122 (1): 17-36.

Martínez Parra M. y Díaz Muñoz, J.A. (2013). Propuesta de zonificación hidrogeológica de las masas de agua subterránea (041.001) Sierra de Altomira y (041.005) Rus-Valdelobos. Boletín Geológico y Minero, 124 (3): 351-365.
Mejías, M. 2007. Caracterización adicional Mancha Occidental I y II. Convenio de colaboración entre la Dirección General del Agua y el Instituto Geológico y Minero de España. Trabajos técnicos para la aplicación de la Directiva Marco del Agua en materia de aguas subterráneas. Centro de Documentación del IGME, Madrid, 103 págs. Informe inédito.

Mejías, M., López Gutiérrez, J., Martínez-Cortina, L. 2012. Características hidrogeológicas y evolución piezométrica de la Mancha Occidental. Influencia del periodo húmedo 2009-2011. Boletín Geológico y Minero. 123 (2) 91-108.

Mejías, M. y del Pozo, J. 2018. Informe sobre la evolución piezométrica de las masas de agua subterránea: 041.007 Mancha Occidental I; 041.006 Mancha Occidental II, 041.005 Rus-Valdelobos, 041.010 Campo de Montiel y 041.001 Sierra de Altomira. Año 2018. Madrid, centro de Documentación del IGME 30 págs. Informe inédito.

Montero, E. 2000. Contribución al estudio de la geometría y los límites del acuífero del campo de Montiel. Instituto de Estudios Albacetenses “Don Juan Manuel". Albacete, 177 págs.

Montero, E. y Rincón, P.J. 2004. Condicionantes geológicos estructurales de la Unidad Hidrogeológica de Campo de Montiel. Il Jornadas sobre el medio natural albacetense. Instituto de Estudios Albacentenses "Don Juan Manuel" de la Excma. Diputación de Albacete, 627-638.

Portero, J.M., Ramírez, J.I. Pérez, A., Gallardo, J., Ancochea, E., Leal, M.C., Aguilar, M.J. y Molina, E., 1988. Mapa Geológico de España E. 1:50.000 (MAGNA). Hoja 760. Daimiel. IGME.

Querol, R. 1989. Geología del subsuelo de la Cuenca delTajo. E.T.S.I. Minas de Madrid (Depto. de Ingeniería Geológica), 48 págs.

Vera, J.A. (editor) (2004). Geología de España. SGE-IGME, Madrid, 890 págs.

Recibido: julio 2019

Revisado: noviembre 2019

Aceptado: enero 2020

Publicado: marzo 2021 